\title{
Isolation and molecular characterization of the stearoyl-CoA desaturase $(S C D)$ gene affecting fat deposition in pigs
}

\author{
Dissertation
}

Submitted for the degree of Doctor of Agricultural Sciences of the Faculty of Agricultural Sciences Georg-August-University Göttingen

Germany

by

Jun Ren

from Jiangxi, P.R.China

Göttingen, December, 2003 


\section{D7}

Referent:

Prof. Dr. Dr. Bertram Brenig

Korreferent:

Prof. Dr. Henner Simianer

Date of oral examination: February 5, 2004 
I would like to dedicate this research to my parents, Shixin Ren and Qiue Xu, my wife Xueping Gao, and my son Gaofei. 


\section{Table of Contents}

Publications

Chapter 1 General introduction

Chapter 2 Assignment of the porcine stearoyl-CoA desaturase (SCD)

gene to SSC14q27 by fluorescence in situ hybridization and by hybrid panel mapping

Chapter 3 Isolation and molecular characterization of the porcine stearoyl-CoA desaturase (SCD) gene

Chapter 4 SCD (stearoyl-CoA desaturase) gene variants and their 36 association with fatness traits in pigs

Summary

Appendix I- SCD mRNA and DNA sequence

Appendix II- List of publications

Appendix III- Curriculum vitae 


\section{Parts of this thesis have been published previously.}

1. Ren J, Knorr C, Habermann FA, Fries R, Huang LS, Brenig B (2003). Assignment of the porcine stearoyl-CoA desaturase (SCD) gene to SSC14q27 by fluorescence in situ hybridization and by hybrid panel mapping. Animal Genetics, 34, 471-473.

2. Ren J, Knorr C, Huang LS, Brenig B (2004). Isolation and molecular characterization of the porcine stearoyl-CoA desaturase (SCD) gene. Gene (accepted with revisions).

3. Ren J, Knorr C, Guo YM, Ding NS, Ai HS, Brenig B, Huang LS (2003). SCD (stearoyl-CoA desaturase) gene variants and their association with fatness traits in pigs. Animal Genetics (submitted). 
1

General Introduction 


\section{Introduction}

Fatness is one of economically important traits in the swine industry. Intense selection for fat production using modern statistical methods has taken place for the past fifty years (Clutter and Brascamp, 1998). At present, most swine breeding schemes aim to decreased fatness and increased lean tissue growth because of the consumer's demand for lean pork. Swine fatness traits have moderate to high heritabilities, permitting effective genetic improvement based solely on phenotypic selection. However, the use of marker-assisted selection (MAS) is expected to yield genetic gain over traditional phenotypic selection. The remarkable developments of molecular biology technologies have open new windows for investigator to identify genes or molecular markers associated with traits of economical importance in farm animals. Current strategies are involved with the chromosome or genome scan approach, the positional candidate gene approach and the direct candidate gene approach (See review by Andersson, 2001). The direct candidate gene approach is the most general and straightforward approach compared to the other two methods. Candidate genes can be identified based on the knowledge of the physiology and biochemistry of a trait. With the development of large number of molecular markers and interval-mapping method, the chromosome and total genome scan approaches have been successfully utilized to dissect quantitative trait loci (QTL) affecting economically important traits such as fatness in pigs. QTLs can be detected in a distinct chromosomal region using the experimental intercross between divergent populations, e.g., European wild boar vs European domestic, Chinese Meishan vs European White. Such verified QTLs may be 
exploited in MAS programs in commercial populations, and causative genes or mutations underlying the phenotypic variance may be ultimately revealed by positional candidate cloning on the basis of the verified QTLs and the comparative mapping knowledge. So far, the genome-wide significant QTLs for fatness have been consistent evidenced on the porcine chromosome 1q, 2p, 4, 6, 7, and X. Moreover, some suggestive QTLs of chromosome-wide significance affecting fatness trait were reported on the porcine chromosome $3,5,10$ and 14. In this thesis, the recent progresses of identification of the major QTLs and the corresponding positional candidate genes for fatness traits in pigs are outlined as follow:

\section{QTLs and positional candidate genes for fatness traits in pigs}

\section{QTLs and positional candidate genes for fatness traits on SSC 4}

The first genome scan for QTLs in pigs used a European wild boar $\times$ Large White (Andersson et al., 1994) and revealed QTLs significantly affecting abdominal fat percentage, growth from birth to 70kg and length of small intestine. The QTLs were all on the porcine chromosome 4, which were confirmed by further analysis with additional markers and different statistical methods (Knott et al., 1998; Marklund et al., 1999; Knott et al., 2002). The best location of QTL was between markers S0175 and ATP1B1 on SSC 4. The QTL was also shown to segregate in a cross between Chinese Meishan and Large white (Walling et al., 1998; Bidanel et al., 2001; Milan et al., 2002), Iberian $\times$ Landrace intercross (Perez-Enciso et al., 2000) and Berlin Miniature×Duroc intercross (Willmers et al., 2002). The QTL locations were fairly 
consistent across all tests (Table 1, Fig. 1). A joint analysis of seven different resource populations confirmed the presence of the QTLs for subcutaneous fat depth on SSC 4 in both Meishan- and wild-boar-derived populations with the location close to the marker S0073 (Walling et al., 2000). It is both of scientific and commercial interest to know if the similar effect can be found within commercial populations. Recently, 11 QTLs for backfat and growth rate previously identified in experimental resource populations were examined for segregation in 10 different commercial populations. The QTL for fatness trait on SSC 4 was the most consistent effect across populations, this QTL was detected for fatness traits in Hampshire, Large white and Pietrain populations, indicating the QTL that explain variation between divergent populations also account for genetic variation within commercial populations (Evens et al., 2003). The finding is of particular importance from breeding point of view for the QTL can be utilized for marker-assisted selection in commercial breeding schemes. A long term goal of QTL mapping is to identify the causative genes and mutations, though it's a very difficult task. The positional candidate gene approach on the basis of comparative mapping knowledge is currently promising strategy to achieve it. Unfortunately, the QTL region is close to the break point of conserved synteny (human chromosome 1 and 8), complicating the identification of possible candidate genes. Indeed, no obvious positional candidate gene has so far been identified in the region. Although the adipocyte fatty acid-binding protein $(A-F A B P)$ gene was assigned to SSC 4 and supposed to control fat deposition in pigs, further studies did not support this hypothesis (Gerbens et al., 2000). Two additional candidate genes, 
$\beta$-3-adrenegic receptor $(A D R B 3)$ and $\mathrm{Na}^{+} / \mathrm{K}^{+}$-ATPase subunit $\beta$ (ATP1B1) gene were within the QTL confidence interval (Knott et al., 1998). However, their effects on fatness traits remain unknown to date.

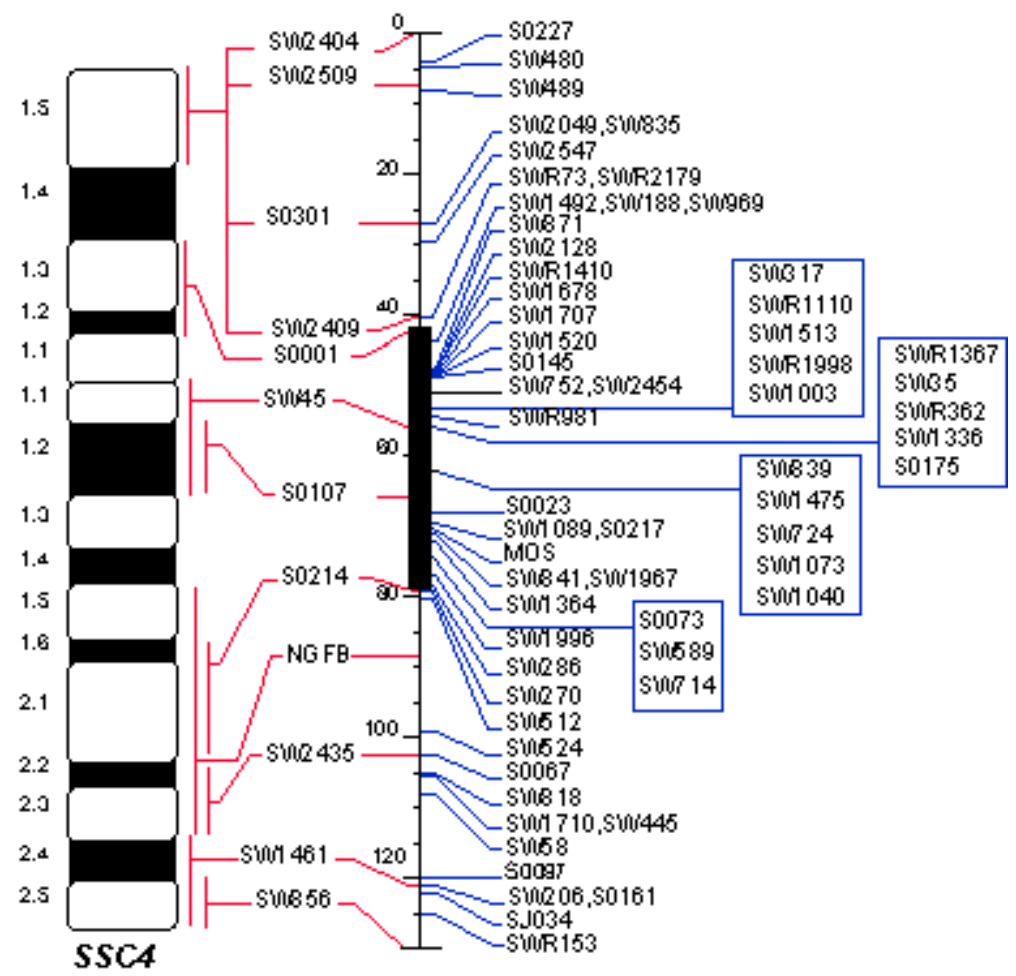

Figure 1 Genomic region for fatness traits on the porcine chromosome 4. The confidence interval of consistently evidenced QTL is indicated by black vertical bar. The map display was based on the USDA-MARC Swine Genome Map (http://www.genome.iastate.edu/maps/marcmap.html).

\section{QTLs and positional candidate genes for fatness traits on SSC 7}

The porcine chromosome 7 contains the swine lymphocyte antigen (SLA) complex, the major histocompatibility complex (MHC) of the sus scrofa species. Many studies indicated the association of the SLA polymorphisms with immunology, production and reproductive traits (see review by Chardon et al., 2000). The QTL significantly affecting fatness traits was consistently evidenced in the region surrounding the SLA region among different Meishan-derived experimental populations (Table 2, Fig. 2). In a Meishan-White Composite reciprocal backcross population, the maximum F-ratio 
Table 1 QTL significantly affecting fatness traits on SSC 4 in different populations.

\begin{tabular}{|c|c|c|c|c|c|c|}
\hline Populations & Institutions & QTL locations & Traits & Favorable allele & Candidates & References \\
\hline $\begin{array}{l}\text { Hampshire, Pietrain and } \\
\text { Large White }\end{array}$ & PIC, UK & Sw35-Sw839 & Fatness & & & $\begin{array}{l}\text { Evans et al., } \\
\text { (2003) }\end{array}$ \\
\hline Meishan $\times$ Large White & INRA, France & S0001-Sw1089 & Backfat thickness & Large White & & $\begin{array}{l}\text { Milan et al., } \\
\text { (2002) }\end{array}$ \\
\hline Meishan $\times$ Large White & INRA, France & S0001-Sw1089 & Backfat thickness & Large White & & $\begin{array}{l}\text { Bidanel et al., } \\
\text { (2001) }\end{array}$ \\
\hline Berlin Miniature $\times$ Duroc & $\begin{array}{l}\text { University of } \\
\text { Bonn, Germany }\end{array}$ & $\begin{array}{l}\text { S0001-S0214; } \\
\text { close to STS_Bio1 }\end{array}$ & $\begin{array}{l}\text { Backfat thickness } \\
\text { eye muscle area, } \\
\text { carcass length }\end{array}$ & Duroc & & $\begin{array}{l}\text { Wimmers et al., } \\
\text { (2002) }\end{array}$ \\
\hline Iberian $\times$ Landrace & $\begin{array}{l}\text { SGIT-INIA } \\
\text { Spain }\end{array}$ & $\begin{array}{l}\text { Sw839-S0214, } \\
\text { close to Sw839 }\end{array}$ & $\begin{array}{l}\text { Backfat thickness, } \\
\text { Backfat weight, } \\
\text { \% linoleic acid }\end{array}$ & Landrace & & $\begin{array}{l}\text { Perez-Enciso } \\
\text { et al., (2000) }\end{array}$ \\
\hline $\begin{array}{l}\text { Joint analysis of seven } \\
\text { resource populations }\end{array}$ & $\begin{array}{l}\text { Roslin institute, } \\
\text { UK }\end{array}$ & Close to $S 0073$ & Backfat thickness & & & $\begin{array}{l}\text { Walling et al., } \\
(2000)\end{array}$ \\
\hline Wild boar $\times$ Large White & Uppsala, Sweden & $\begin{array}{l}\text { S0175-ATP1B1, } \\
\text { close to } S 0107\end{array}$ & $\begin{array}{l}\text { Backfat thickness, } \\
\text { \% abdominal fat }\end{array}$ & Large white & $\begin{array}{l}\text { ADRB3, } \\
\text { ATP1B1 }\end{array}$ & $\begin{array}{l}\text { Knott et al., } \\
\text { (1998) }\end{array}$ \\
\hline Meishan $\times$ Large White & Roslin , UK & S0175-GBA & Backfat thickness & Large White & & Walling (1998) \\
\hline
\end{tabular}


of the QTL for six backfat thickness measures was close to the location of the tumor necrosis factor alpha $(T N F \alpha)$ gene, which was located in the SLA region (Rohrer, 2000; Rohrer and Keele, 1998a). The QTL effects were also detected in Iowa State University resource families within the same region that was near $T N F \alpha$ (Wang et al., 1998). The existence of QTL influencing fatness on SSC 7 was further confirmed by analyzing other Meishan-White populations. The QTL was localized a 33-cM confidence interval (Sw1369-S0102) in a Meishan $\times$ Dutch Large White and Landrace $F_{2}$ cross (Rattink et al., 2000). In the INRA QTL experiment, the most likely QTL location was supposed to be between the SLA and marker S0102 (Milan et al., 2002). A striking characteristic of the QTL across all populations was that the obesity decreasing allele was originated from Meishan pig, irrespective of its obese phenotype. Wada et al (2000) also reported a significant QTL for back fat thickness around the SLA region on SSC 7 in a Meishan $\times$ Goettingen Miniature cross population. Moreover, The greatest evidence for QTL for back fat was detected in an 80-cM interval around the SLA (TNFB-S0101) in a Berkshire $\times$ Yorkshire resource family. Different from the Meishan cryptic allele for leanness, Berkshire alleles were associated with considerably greater fatness in that study as expected from breed differences (Malek et al., 2001). It is interesting to note that the highly selected commercial populations are recently evidenced for the presence of the QTL for fatness (Nagamine et al., 2003). The maintenance of such QTL (alleles) in commercial populations indicates its strong pleiotropic effects, presumably on fitness traits such as survival and fertility. The major QTL for fatness trait detected in experimental cross also explains the considerable phenotypic variance in commercial populations and have not yet reached fixation through the process of artificial selection, supporting its encouraging application in MAS programs in pig breeding. 
The consistent findings for the QTL near the SLA region on SSC 7 indicate that this QTL is real and has generally large effects on fat deposition in pigs. Comparative mapping of the SLA region was performed using IMpRH panel to supply positional candidate genes underlying the QTL effects. The SLA is assigned in the SSC 7p12-q12 region and homologous to HSA 6p23-q12 harboring human MHC (Demeure et al., 2003). A global conservation of gene order and distance was revealed between the two MHC regions with the exception of a 3.7-Mb rearranged fragment. The Colipase (CLPS) and bone morphogenetic protein 5 (BMP5) genes within the SLA region were proposed as positional candidate genes (Demeure et al., 2003). CLPS prevents the inhibition of pancreatic lipase activity by surface-active agent such as bile salts by binding the enzyme to its triacylglycerol substrate. CLPS gene was mapped to the QTL interval between the TNFB and S0102 (Brown and Archibald, 2002). BMP5 influences the skeleton development and is required for normal development of several soft tissues (King et al., 1994). However, it should be mentioned that the SLA has a high gene density and is highly polymorphic, numerous genes might be considered as positional candidate genes in this region. 


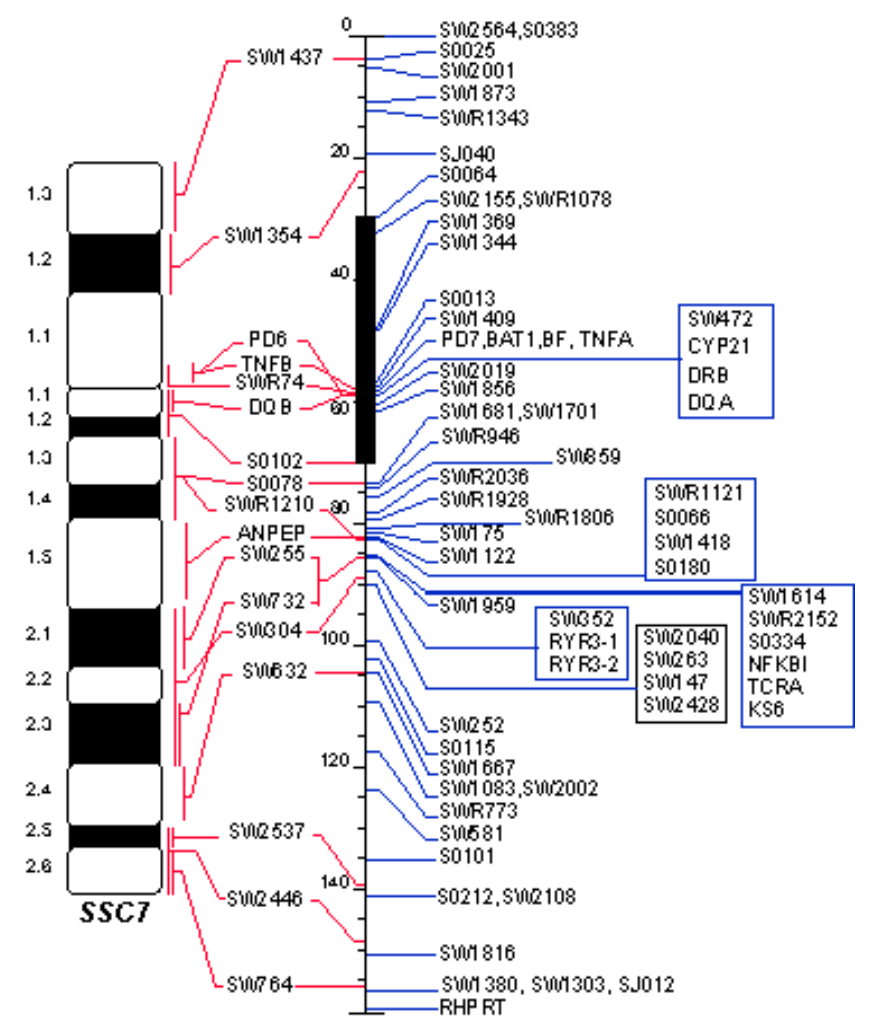

Figure 2 Genomic region for fatness traits on the porcine chromosome 7. The confidence interval of consistently evidenced QTL is indicated by black vertical bar. The map display was based on the USDA-MARC Swine Genome Map (http://www.genome.iastate.edu/maps/marcmap.html). 
Table 2 QTL significantly affecting fatness traits on SSC 7 in different populations.

\begin{tabular}{|c|c|c|c|c|c|c|}
\hline Populations & Institutions & QTL Locations & Traits & Favorable allele & Candidates & References \\
\hline $\begin{array}{l}5 \text { western commercial } \\
\text { pig populations }\end{array}$ & Roslin institute, UK & TNFB-SLA & Fatness & Meishan & & $\begin{array}{l}\text { Nagamine et al., } \\
\text { (2003) }\end{array}$ \\
\hline Meishan $\times$ Large White & INRA, France & SLA-S0102 & All fatness traits & Meishan & & $\begin{array}{l}\text { Milan et al., } \\
\text { (2002) }\end{array}$ \\
\hline Meishan $\times$ Large White & INRA, France & SLA-S0102 & $\begin{array}{l}\text { BF14w, 17w, 22w } \\
\text { BF40kg, BF60kg }\end{array}$ & Meishan & $\begin{array}{l}\text { BMP5; } \\
\text { CLPS }\end{array}$ & $\begin{array}{l}\text { Bidanel et al., } \\
\text { (2001) }\end{array}$ \\
\hline Berkshire $\times$ Yorkshire & $\begin{array}{l}\text { Iowa State University, } \\
\text { USA }\end{array}$ & $\begin{array}{l}\text { TNFB-S0101 } \\
(80 \mathrm{cM})\end{array}$ & Backfat thickness & Yorkshire & & $\begin{array}{l}\text { Malek et al., } \\
\text { (2001) }\end{array}$ \\
\hline $\begin{array}{l}\text { Meishan } \times \text { Dutch Large } \\
\text { White or Landrace }\end{array}$ & $\begin{array}{l}\text { University of Wageningen, } \\
\text { The Netherlands }\end{array}$ & $\begin{array}{l}\text { Sw1369-S0102 } \\
(33 \mathrm{cM})\end{array}$ & Backfat thickness & Meishan & & $\begin{array}{l}\text { Rattink et al., } \\
(2000)\end{array}$ \\
\hline $\begin{array}{l}\text { Meishan } \times \text { Dutch Large } \\
\text { White or Landrace }\end{array}$ & $\begin{array}{l}\text { University of Wageningen } \\
\text { The Netherlands }\end{array}$ & SLA-Sw1856 & Backfat thickness & Meishan & & $\begin{array}{l}\text { de Koning et al., } \\
\text { (2000) }\end{array}$ \\
\hline $\begin{array}{l}\text { Goettingen Miniature } \\
\times \text { Meishan }\end{array}$ & NIAI, Japan & $\begin{array}{l}\text { Swr1078-TNFB } \\
\text { Sw1369-S0102 }\end{array}$ & Backfat thickness & & & $\begin{array}{l}\text { Wada et al., } \\
\text { (2000) }\end{array}$ \\
\hline
\end{tabular}


Table 2 QTL significantly affecting fatness traits on SSC 7 in different populations (continued).

\begin{tabular}{|c|c|c|c|c|c|c|}
\hline Meishan $\times$ Dutch Large & Wageningen University, & S0064-S0102- & Backfat thickness & Meishan & & de Koning et al., \\
\hline $\begin{array}{l}\text { Meishan } \times \text { White } \\
\text { reciprocal backcross }\end{array}$ & USDA, USA & 5cM after SLA & $\begin{array}{l}\text { Backfat thickness } \\
\text { at } 14 \text { and } 26 \text { weeks }\end{array}$ & Meishan & & $\begin{array}{l}\text { Rohrer } \\
(2000)\end{array}$ \\
\hline $\begin{array}{l}\text { Meishan or Minzhu × } \\
\text { Duroc or Hampshire } \\
\text { or Landrace }\end{array}$ & $\begin{array}{l}\text { Iowa State University, } \\
\text { USA }\end{array}$ & $\begin{array}{l}\text { S0064-S0102, } \\
\text { close to TNF } \alpha\end{array}$ & Backfat thickness & Meishan & $\begin{array}{l}\text { TNF } \alpha \\
\text { CLPS }\end{array}$ & $\begin{array}{l}\text { Wang et al., } \\
\text { (1998) }\end{array}$ \\
\hline Pietrain $\times$ Large White & $\begin{array}{l}\text { University of Liege, } \\
\text { Belgium }\end{array}$ & S0066-Sw252 & $\%$ Belly fat & Pietrain & & $\begin{array}{l}\text { Nezer et al., } \\
\text { (2002) }\end{array}$ \\
\hline
\end{tabular}

BF14w, 17w, 22w: Average backfat thickness at 14, 17 and 22 weeks; BF40kg, BF60kg: Average backfat thickness at 40 and $60 \mathrm{~kg}$ live weight;

$\%$ Belly fat= belly weight/carcass weight. 


\section{QTLs and positional candidate genes for fatness traits on SSC $2 p$}

A whole genome scan using a Pietrain $\times$ Large White intercross initially revealed a parentally imprinted QTL with major effects on fat deposition and muscle mass at the centromeric end of chromosome 2 (Nezer et al., 1999; Fig. 3). The result was confirmed at the same location in the same population with additional markers and production traits. The imprinted QTL was evidenced for three fatness traits (backfat thickness, \% back fat and \% fat cut) and three muscularity traits (\% loin, \% ham and \% lean cut) (Nezer et al., 2002). Meanwhile, this QTL was shown to segregate in a European wild boar $\times$ Large White intercross and explained $10-20 \%$ of the variation in backfat thickness and $15-30 \%$ of the phenotypic variation in muscle mass (Jeon et al., 1999). For the distal end of p arm of SSC 2, the homologous human region is HAS 11p, encompassing several imprinting genes including the parentally imprinting insulin-like growth factor 2 (IGF2) gene. Hence, the IGF2 locus was considered as a strong positional candidate gene in the region (Nezer et al., 1999). However, initial screening of polymorphisms in the coding and regulatory regions of the IGF2 gene failed to find any causative mutations. To uncover causative mutations underlying the QTL, a haplotype sharing approach was used to refine the QTL location. The QTL was narrowed in an 250 -kb interval between the markers 370SNP6/15 and SWC9, which contains IGF2 and insulin (INS) gene as the only known paternally expressed genes (Nezer et al., 2003). Further analysis provided convincing evidences that a G /A transition in intron 3 of IGF2 (at position 3072 nucleotide) is the causative mutation explaining the effects of the QTL. The wild type (G) binds a nuclear factor, probably a 
repressor and this interaction is abrogated by the mutation (A), resulting in an increase in IGF2 mRNA expression in postnatal muscle and consequently higher muscle mass and lower fat deposition (Van Laere et al., 2003). This extraordinary finding indicates that regulatory mutations in the non-coding intronic region are also important for controlling phenotypic variation besides the polymorphisms in the coding and flanking regulatory regions.

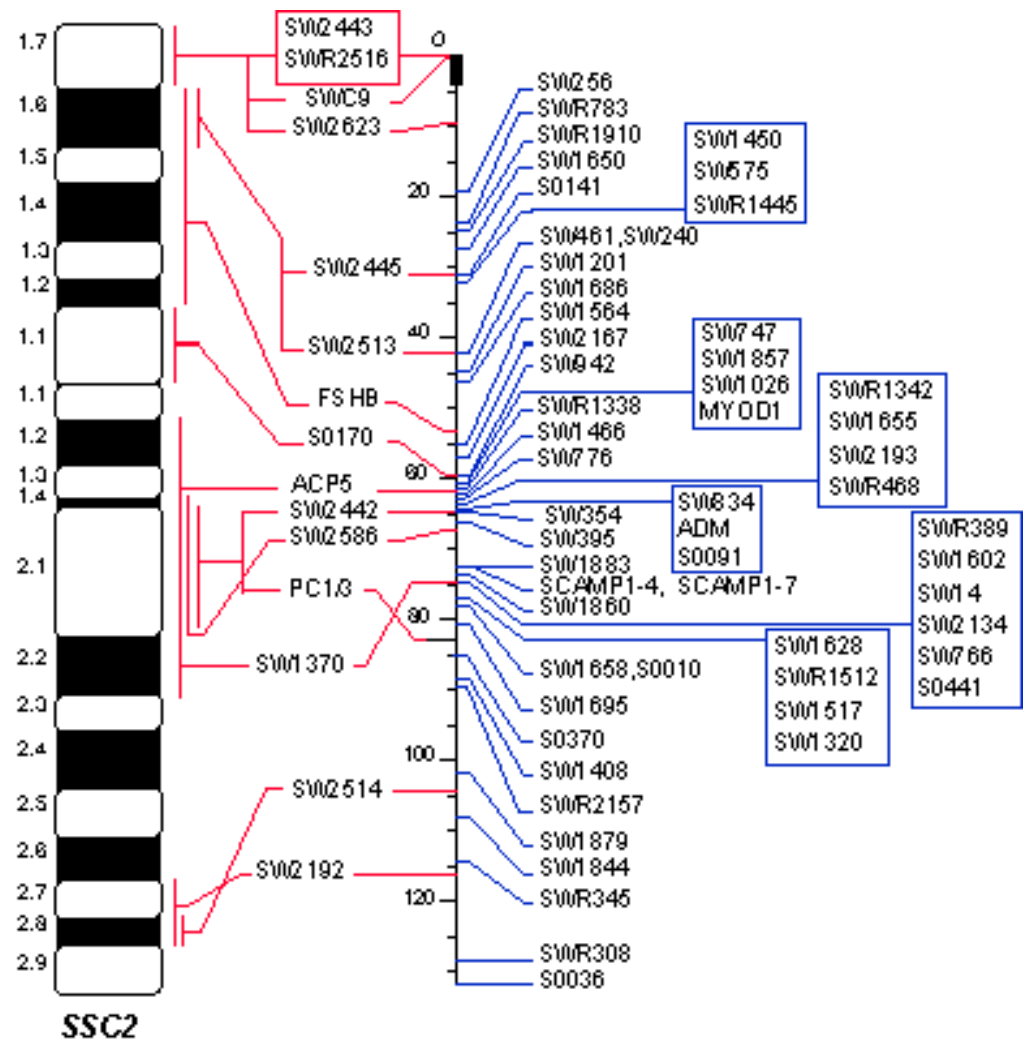

Figure 3 Genomic region for fatness traits on the porcine chromosome 2p. The confidence interval of consistently evidenced QTL is indicated by black vertical bar. The map display was based on the USDA-MARC Swine Genome Map (http://www.genome.iastate.edu/maps/marcmap.html).

It should be noted that a different paternally expressed QTL for back fat thickness was found at $35 \mathrm{cM}$ from the IGF2 region in an experimental cross between Meishan pigs and commercial Dutch pigs (de Koning et al., 2000; Rattink et al., 2000). So far, no promising positional candidate gene has been proposed, partially due to the fact 
that the QTL region is crossing the breakpoint of two conserved synteny group, HSA 11 and HSA 19. The extremity of SSC 2p was also evidenced for one QTL affecting both lean and, to a lesser extent, fat tissue weights in the INRA Meishan $\times$ Large White $\mathrm{F}_{2}$ populations. The position was quite similar to the IGF2 region. However, the QTL did not exhibit any significant imprinting effect (Milan et al., 2002), supporting the finding that the IGF2 causative mutation was just present in some founders of different experimental resource populations (Van Laere et al., 2003).

\section{QTLs and positional candidate genes for fatness traits on SSC 1q}

A genome-wide significance was evidenced for fatness and growth traits in the telomeric region of the SSC $1 \mathrm{q}$ in several studies involved Meishan $\times$ White pig intercross populations and Meishan synthetic lines (Fig. 4). This region was shown to influence backfat depth, loin eye area and trimmed wholesale product weight in the USDA resource families, the Meishan allele tended to increase the backfat depth (Rohrer, 2000; Rohrer and Keele, 1998a, b). The genomic area was also identified as affecting backfat thickness in a cross between Meishan and Dutch Large White and Landrace lines (de Koning et al., 1999). Moreover, strong evidences for QTL were found for lean and fat cut weight, backfat thickness and postweaning growth rate at the same region, i.e. the end of SSC $1 q$ and close to the $S w 1301$ markers in the INRA Meishan $\times$ Large White experimental population (Milan et al., 2002; Bidanel et al., 2001). These results were in good agreement with the recent finding that the QTL effects were confirmed in a Meishan synthetic line (Evens et al., 2003). In this QTL 
region, the steroidogenic factor $1(S F 1)$ and LIM homeodomain transcription factor (Lhx3) gene were identified and considered candidate genes for this QTL due to their position and physiological role (Smith et al., 2001).

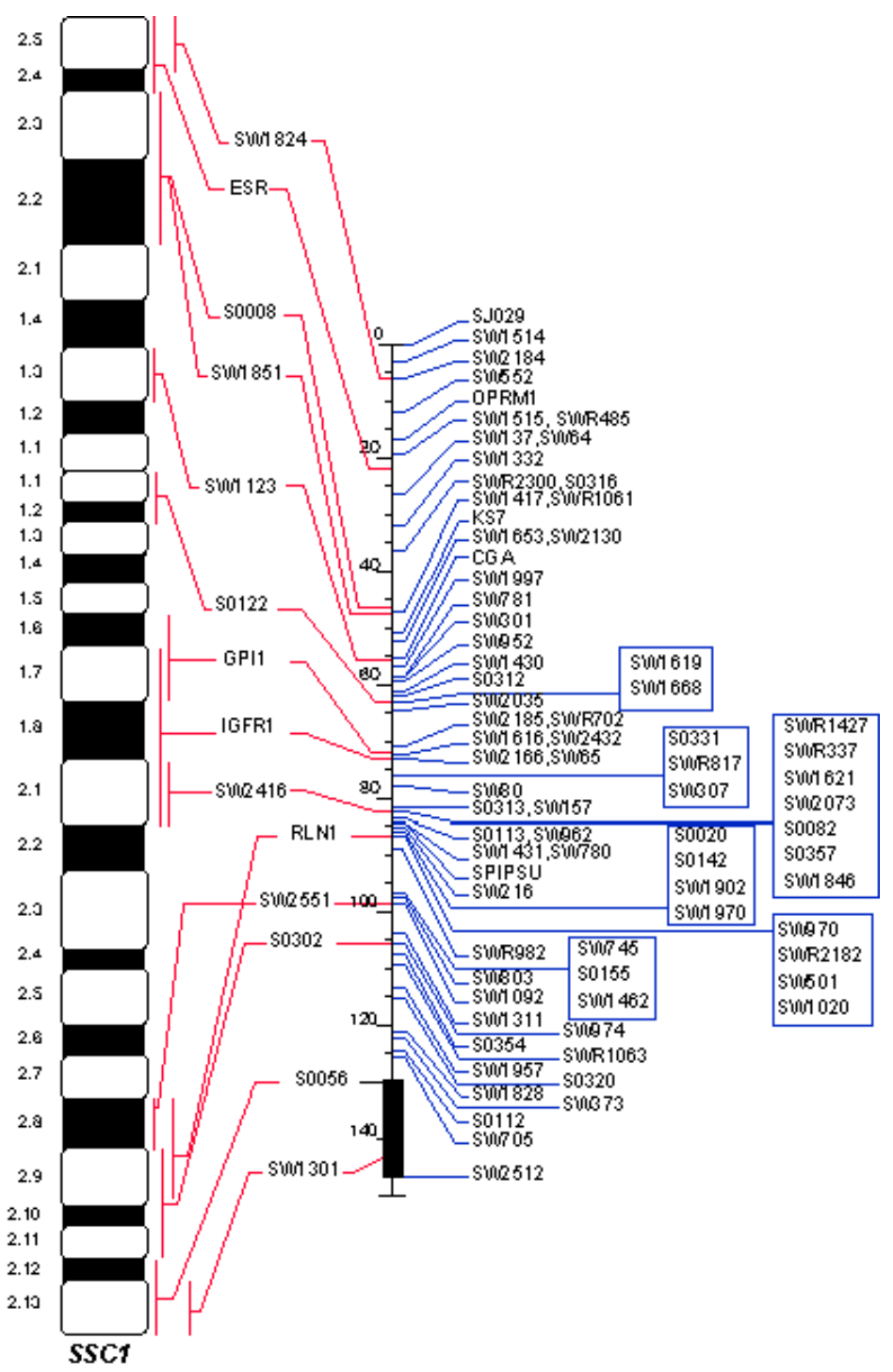

Figure 4 Genomic region for fatness traits on the porcine chromosome 1q. The confidence interval of consistently evidenced QTL is indicated by black vertical bar. The map display was based on the USDA-MARC Swine Genome Map (http://www.genome.iastate.edu/maps/marcmap.html).

\section{QTLs and positional candidate genes for fatness traits on SSC 6}

A QTL for backfat thickness and intramuscular fat (IMF) content was identified on 
the porcine chromosome 6 in a $F_{2}$ cross between Iberian $\times$ Landrace pigs. The most likely position of the QTL is in the interval between the markers S0228 and Sw1881 and the maximum F-ratio is close to Sw1881 (Óvilo et al., 2000; Fig. 5). So far this genome-wide significant QTL has not been detected in other Meishan or European wild boar derived resource populations, indicating that the Iberian genetic background is partially different from that of Meishan and European wild boar. Two positional candidate genes within the QTL region, i.e. the heart fatty acid-binding protein $(H-F A B P)$ and the leptin receptor $(L E P R)$ gene were utilized for fine mapping of the QTL region in combination of seven microsatellite markers using the same experimental population. The QTL effects on fatness and IMF were confirmed and mapped in the same marker bracket (Óvilo et al., 2002). The H-FABP protein is involved in the intracellular transport of fatty acids in skeletal muscle and plays an important role in lipid metabolism. A HaeIII restriction fragment length polymorphism (RFLP) in the intron 2 of the $H$-FABP was initially indicated to be associated with fatness traits in the Duroc breed (Gerbens et al., 1999). However, more recent works have described this association with only IMF (Gerbens et al., 2000). In the Iberian $\times$ Landrace $\mathrm{F}_{2}$ population, the $H$-FABP polymorphism showed significant effects on IMF and eye muscle area in an animal model (Óvilo et al., 2002). Due to its interaction with leptin, the $L E P R$ gene is related to the control of feed intake and the regulation of energy balance in mammals (Ruiz-Cortes et al., 2000). A HpaII-RFLP in the fourth intron of the LEPR gene showed significant effects on backfat thickness and IMF in the Iberian $\times$ Landrace $F_{2}$ population in an animal model 
(Óvilo et al., 2002). However, when the candidate gene effect was included in a QTL regression analysis, both the $H-F A B P$ and $L E P R$ associations were not observed, suggesting that they must not be the causative mutations for the QTL but only markers in linkage disequilibrium with them (Óvilo et al., 2002). Hence, Polymorphisms in other positional candidate genes or new polymorphisms in the coding and regulatory regions of the $H-F A B P$ and $L E P B$ genes are required to identify the causative mutations underlying the QTL effects on SSC 6.

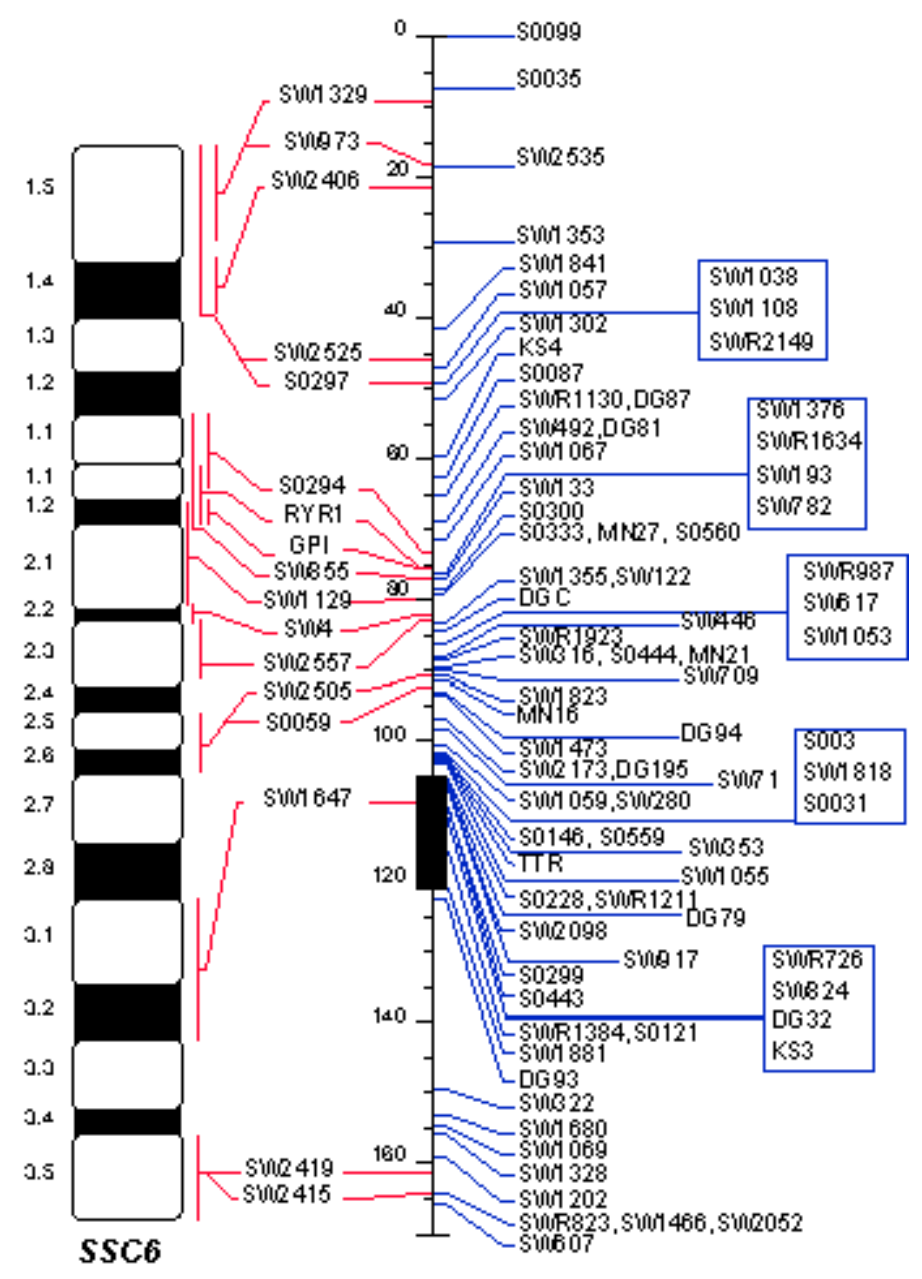

Figure 5 Genomic region for fatness traits on the porcine chromosome 6 . The confidence interval of the QTL is indicated by black vertical bar. The map display was based on the USDA-MARC Swine Genome Map (http://www.genome.iastate.edu/maps/marcmap.html). 


\section{QTLs and positional candidate genes for fatness traits on SSC X}

Several studies reported the presence of a QTL for fatness traits on the porcine chromosome X (Fig. 6). Significant QTL was detected on SSC X in the USDA resource population, which significantly affected backfat thickness and leanness traits including loin area and trimmed wholesale product weight (Rohrer and Keele, 1998a, b). This genomic region (in the interval between the markers $S w 2456$ and $S w 2476$ ) was also evidenced for the existence of a QTL affecting backfat thickness in a Meishan $\times$ Dutch White pigs intercross (Harlizius et al., 2000). In the INRA QTL experiment, a significant QTL was identified for backfat, ham and loin weight in the similar region (near the marker Sw1994 on SSC X), with favourable effects of Large White alleles. The QTL effects explain 36 and 41\% of phenotypic variance of loin and backfat weight, respectively (Milan et al., 2002). These consistent findings support the reliability of the QTL in this region. Two candidate genes, the androgen receptor $(A R)$ and the phosphoglycerate kinase 1 (PGK1) were located within the QTL region on the basis of comparative mapping (Harlizus et al., 2000). However, their associations with fatness traits in pigs remain to be seen to date. 


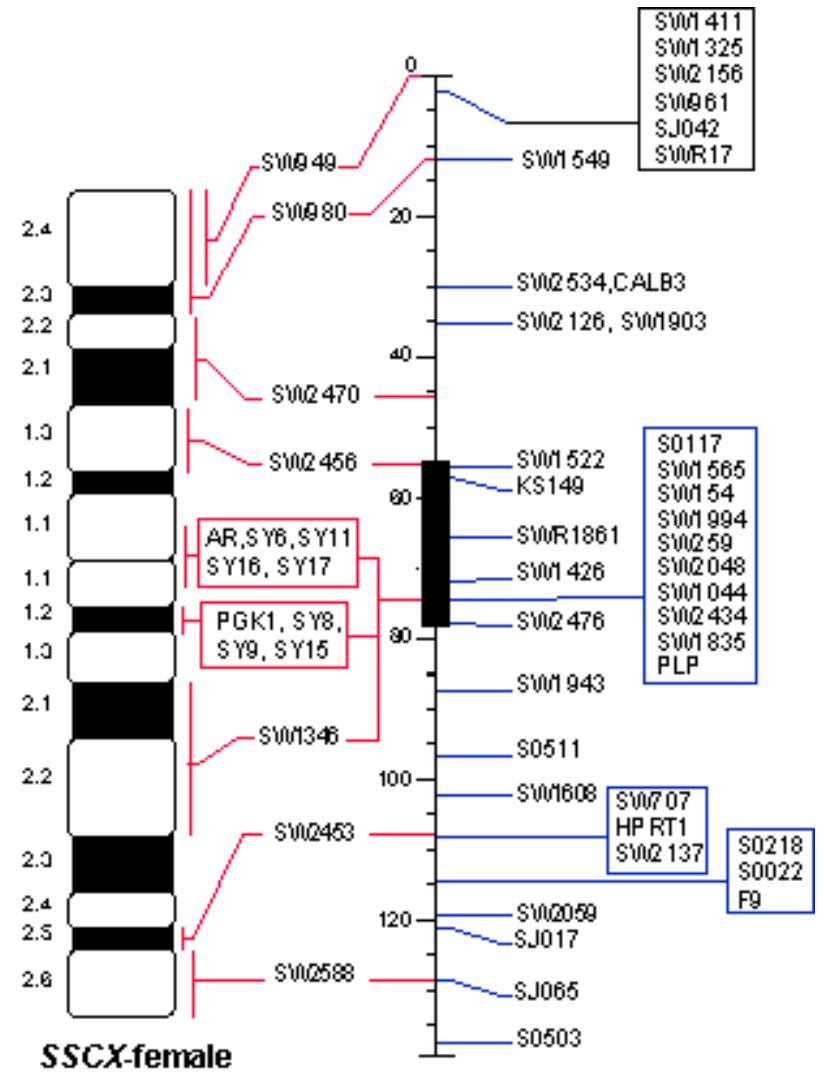

Figure 6 Genomic region for fatness traits on the porcine chromosome $\mathrm{X}$. The confidence interval of consistently evidenced QTL is indicated by black vertical bar. The map display was based on the USDA-MARC Swine Genome Map (http://www.genome.iastate.edu/maps/marcmap.html). 


\section{$S C D$ : the candidate gene for fatness traits in pigs}

\section{The discovery of leptin gene}

In 1994, Friedman and his colleagues identified an obesity-decreasing gene designated by leptin by tracing the genes in a mutant strain of extremely obese mice (Zhang et al., 1994). It was the identification of leptin gene that opens the door to the obesity research in mammals. Leptin is a $16-\mathrm{kDa}$ protein secreted from white adipocyte. It has been implicated in the regulation of feed intake, energy expenditure, whole-body energy balance and neuroendocrine axis in mammals (Campfield et al., 1995). The leptin-deficient mice (ob/ob) are extremely obese, and administration of leptin protein into $o b / o b$ mice resulted in reduced feed intake, weight loss and improved reproduction (Zhang et al., 1994). Leptin is believed to produce weight loss by decreasing the animals’ appetite while at the same time revving up their metabolic rate. Plasma leptin has been demonstrated to infuse into the arcuate nucleus in the hypothalamus and inhibit the neuropeptide Y (NPY) and agouti-related peptide (AgRP), causing the reduced appetite and metabolism. Meanwhile, Leptin stimulates the POMC/CART neurons and activates the release of $\alpha$-melanocyte-stimulating hormone (MSH), consequently inhibiting eating (Marx, 2003).

Because of its physiological properties in the energy metabolism, the leptin gene has been considered as a strong candidate gene controlling obesity in livestock. Plasma leptin levels in cattle and sheep increase linearly with increased body fat mass and with increased energy balance (Delavaud et al., 2000; Ehrhardt et al., 2000). A cytosine (C) to thymine (T) missense mutation was identified in exon 2 of the bovine 
leptin gene, and the $\mathrm{T}$ allele appeared to be associated with fatter carcasses and higher leptin mRNA level (Buchanan et al., 2002). In swine, the leptin gene is exclusively expressed in adipose tissue, and leptin mRNA level in sera was reported to be greater in adipose tissue from obese pigs than lean pig (McNeel et al., 2000). The porcine leptin gene consists of three exons, and a 504-bp open reading frame encodes a peptide of 167 amino acids (Bidwell et al., 1997). Seven non-invasive single nucleotide polymorphisms (SNPs) were characterized in the porcine leptin gene. Kennes et al (2001) presented a possible association between the A2845T and T3469C SNPs with feed intake and growth rate traits in Landrace pigs. The T3469C polymorphism was also suggested to affect fatness in pigs (Jiang and Gibson, 1999). Nevertheless, those evidences are not conclusive, for those mutations do not alter the encoding protein structure and so far none of interval confidence of major QTL for fatness in pigs harbors the leptin gene. Linkage disequilibrium with another causative mutations was proposed to be more likely explanation of the association (Jiang and Gibson, 1999). In human, several studies indicated the polymorphisms in the leptin gene were not the primary cause of obesity (Carlsson et al., 1997), though some rare case of human obesity caused by leptin deficiencies were treatable by the hormone. For this reason, numerous studies have been focused on the biochemical pathways through which leptin works to uncover other obesity regulators since the discovery of leptin gene.

\section{SCD gene is a key component in the leptin-signaling pathway}

To pinpoint the most important leptin-regulated gene, DNA microarrays were used to 
compare the transcription profiles between the leptin-treated $o b / o b$ mice and the food restriction group. Stearoyl-CoA desaturase-1 (SCD-1) gene was most prominent in six clusters of genes specifically regulated by leptin (Cohen et al., 2002). Leptin was found to specifically repress RNA level and enzymatic activity of $S C D-1$ gene. $S C D-1$ RNA levels were highly elevated in $o b / o b$ mice liver, whereas normalized at 2 days after treated by leptin. To elucidate whether SCD-1 mediate the leptin's metabolic effects, Cohen et al. (2002) intercrossed the leptin-deficient ob/ob mice and the $a b^{J} / a b^{J}$ mice with naturally occurring mutations in $S C D-1$. It was notable that double-mutant $a b^{J} / a b^{J}$; $o b / o b$ mice were significantly less obese than $o b / o b$ controls and had markedly increased energy expenditure. The $o b / o b$ mice were characterized for massively enlarged livers that were engorged with lipid, and had high levels of liver triglyceride and very low density lipoprotein (VLDL). However, the ob/ob mice with mutations in $S C D-1$ had normal livers with significantly reduced triglyceride storage and VLDL production. These data suggest that SCD-1 is an important biological modulator of lipid metabolism and indicate that SCD-1 is required for the fully developed obese phenotype of $o b / o b$ mice, and down-regulation of SCD-1 is an important component of leptin’s metabolic actions.

\section{The role of SCD gene in lipid metabolism}

Stearoyl-CoA desaturase is a key enzyme in the cellular biosynthesis of monounsaturated fatty acids. It is located in the endoplasmic reticulum membrane and catalyzes the insertion of a double bond between carbon atoms 9 and 10 in a spectrum of saturated fatty acids. The preferred substrates are stearoyl-CoA (C18:0) and 
palmitoyl-CoA (C16:0), which are converted to oleic acids (C18:1) and palmitoleic acids (C16:1) by SCD enzyme, respectively (Enoch et al., 1976). The oxidative reaction is catalyzed by a set of microsomal electron-transport proteins composed sequentially of $\mathrm{NADH}$ cytochrome b5 reductase, cytochrome b5 and the terminal SCD (Fig. 7). Stearoyl-CoA desaturase is the rate-limiting component in this reaction.

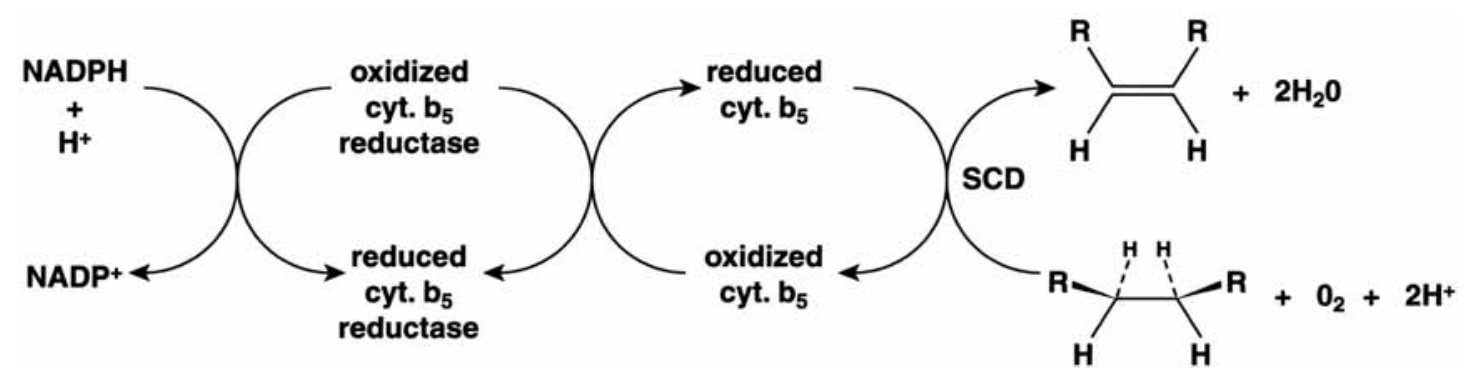

Figure 7 The pathway of electron transfer in the desaturation of fatty acids by SCD.

It has been shown that a deficiency of SCD-1 ameliorates the obesity of $o b / o b$ mice and completely corrects the hypometabolic phenotype of leptin deficiency (Cohen et al., 2002). The SCD-1 deficient mice (SCD1-/-) were also found to reduce body adiposity despite the increased feed intake, increase insulin sensitivity and be resistant to diet-induced weight gain (Ntambi et al., 2002). Furthermore, Stearoyl-CoA desaturase has been implicated as a nutritional target for lipid lowering; the beneficial effects of dietary (n-3) fatty acids for lowering serum lipids in rodents are due in part to decreased expression of SCD gene (Kramer et al., 2003). These observations suggest that $S C D$ gene is a central lipogenic enzyme, playing an essential role in the lipid metabolism. Several explanations have been postulated for the molecular basis of the lipid-lowering effects of SCD deficiency, through it is not yet fully understood.

The revving up fatty acid oxidation may account for the decreasing body fat caused 
by $S C D$ deficiency. The deletion of $S C D-1$ gene was reported to up-regulate the lipid oxidation enzymes such as acyl-CoA oxidase, very long chain acyl-CoA dehydrogenase and carnitine palmitoyltransferase-1 (CPT-1) gene in mice (Ntambi et al., 2002). All these genes are targets of peroxisome proliferators-activated receptor $\alpha$ $(P P A R \alpha)$ and contain PPAR $\alpha$ response region in their promoters. Changes in SCD-1 activity presumably alter the levels of ligand for PPAR $\alpha$, resulting in an increased expression of PPARa and consequently an increased expression of PPAR $\alpha$-targeted lipid oxidation enzymes. Moreover, if $S C D$-1 gene is blocked, the intercellular levels of saturated fatty acyl-CoAs will build up and inhibit acetyl-CoA carboxylase (ACC) through a well-known feedback mechanism, reducing cellular levels of malonyl CoA. Malonyl CoA is a key control point of the lipid $\beta$-oxidation. It inhibits CPT-1 gene controlling the import and oxidation of fatty acids in mitochondria. Hence, the reduced levels of malonyl CoA will stimulate fatty acids import to mitochondria, resulting in an increased lipid oxidation (Ntambi et al., 2002).

An impaired triglyceride and cholesterol biosynthesis could partially underlie the adiposity-loss effects of SCD deficiency. The oleic and palmitoleic fatty acids, the products of SCD enzyme, are main components of triglyceride and cholesterol, which are required for hepatic lipid storage and VLDL synthesis. It had been reported that the $S C D$-1 deficient mice had very low levels of triglycerides in the VLDL and low density lipoprotein fractions compared with normal animals (Miyazaki et al., 2000). A lipogenic diet failed to induce triglyceride synthesis in the $S C D-1$ deficient mice, despite the incorporation of oleate into the liver. Only endogenous monounsaturated 
fatty acids produced by $S C D-1$ gene are required for triglyceride synthesis in mice liver (Miyazaki et al., 2001). Meanwhile, the deletion of SCD-1 gene was shown to down-regulate sterol regulator element binding protein-1 (SREBP-1) gene and its targeted lipogenic genes such as fatty acids synthase (FAS) and glycerol phosphate acyl-CoA transferase (GPAT) gene, thereby reducing triglyceride synthesis and storage (Ntambi et al., 2002). These data indicate that $S C D$-1 gene expression is a key control point in the induction of triglyceride synthesis in liver.

Alternative mechanisms may also explain the adiposity-loss effects of SCD deficiency. It is well established that the ratio of saturated to unsaturated fatty acids incorporated into phospholipids determines the membrane fluidity. Hence, Changes in SCD activity could alter the membrane fluidity by altering the ratio of saturated to unsaturated fatty acids, which could affect signal transduction. It should be mentioned that alterations of this ratio have been implicated in various disease state including hypertension, neurological diseases, immune disorders and cancer in addition to adiposity (see review by Ntambi, 1999).

In summary, stearoyl-CoA desaturase is a rate-limiting enzyme in the biosynthesis of monounsaturated fatty acids. It plays a crucial role in regulating the body weight and adiposity in the complex leptin-signaling pathway, spurring $S C D$ gene as a strong candidate gene for obesity in mammals.

\section{Characterization of SCD genes in mammals}

SCD genes have been so far characterized in several mammals including mouse, rat (Mihara, 1990), human (Zhang et al., 1999), goat (Bernard et al., 2001) and sheep 
(Ward et al., 1998). The murine SCD gene was first isolated and cloned by Ntambi and his colleagues in 1988 (Ntambi et al, 1988). Since than, three additional murine SCD genes have been characterized. Their encoding regions and predicted proteins are highly homologous, whereas their expression profiles differ remarkably. SCD1 is mainly expressed in adipose tissues and liver (Ntambi et al., 1988), SCD2 is principally expressed in brain (Kaestner et al., 1989), SCD3 is skin-specifically expressed (Zheng et al., 2001), whereas SCD4 is exclusively expressed in the heart (Miyazaki et al., 2003). The reasons for having four SCD gene isoforms in mice remain to be seen. In human, one functional SCD gene was identified on chromosome 10, which generated two alternative transcripts of 3.9 and $5.2 \mathrm{~kb}$. An inactive, fully processed pseudogene was located on human chromosome 17 (Zhang et al., 1999). In sheep and goat, SCD mRNA is transcribed from a single gene, which was assigned to ovine chromosome 22q21 (Bernard et al., 2001; Ward et al., 1998). So far, only a 1,003-bp porcine SCD mRNA sequence was deposited in the database (GenBank accession no. Z97186). The sequence was incomplete, especially lacking the start and stop codon. The aim of this study is to isolate and characterize the complete porcine SCD gene, and to elucidate its association with fatness traits in pigs. The chromosomal assignment, the genomic organization, the complete cDNA and genomic DNA sequence of the porcine $S C D$ gene, the expression profiles in different tissues, the gene polymorphisms among different pig breeds and their association with fatness traits in a White Duroc $\times$ Chinese Erhualian $F_{2}$ population were described in this thesis. 


\section{References}

Andersson L, Haley CS, Ellegren H, Knott SA, Johansson M, Andersson K, Andersson-Eklund L, Edfors-Lilja I, Fredholm M, Hannsson I (1994). Genetic mapping of quantitative trait loci for growth and fatness in pigs. Science, 265, 1771-1774.

Andersson L (2001). Genetic dissection of phenotypic diversity in farm animals. Nat Rev Genet, 2, 130-138.

Bernard L, Leroux C, Hayes H, Gautier M, Chilliard Y, Martin P (2001). Characterization of the caprine stearoyl-CoA desaturase gene and its mRNA showing an unusually long 3'-UTR sequence arising from a single exon. Gene, 281, 53-61.

Bidanel JP, Milan D, Iannuccelli N, Amigues Y, Boscher MY, Bourgeois F, Caritez JC, Gruand J, Roy PL, Lagant H, Quintanilla R, Renard C, Gellin J, Ollivier L, Chevalet C (2001). Detection of quantitative trait loci for growth and fatness in pigs. Genet Sel Evol, 33, 289-309.

Bidwell CA, Ji S, Frank GR, Cornelius SG, Willis GM, Spurlock M (1997). Cloning and expression of the porcine obese gene. Anim Biotechnol, 8, 191-206.

Brown JF and Archibald AL (2002). Physical and genetic mapping of the porcine colipase gene (CLPS). Anim Genet, 33, 377.

Buchanan FC, Fitzsimmons CJ, van Kessel AG, Thue TD, Winkelman-Sim DC, Schmutz SM (2002). Association of a missense mutation in the bovine leptin gene with carcass fat content and leptin mRNA levels. Genet Sel Evol, 34, 105-116.

Campfield LA, Smith FJ, Guisez Y, Devos R, Burn P (1995). Recombinant mouse OB protein: evidence for a peripheral signal linking adiposity and central neural networks. Science, 269, 546-549.

Carlsson B, Lindell K, Gabrielsson B, Karlsson C, Bjarnason R (1997). Obese (ob) gene defects are rare in human obesity. Obes Res, 5, 30-35.

Chardon P, Renard C, Rogel-Gaillard C, Vaiman M (2000). The pig major histocompatibility complex and related paralogous regions: a review. Genet Sel 
Evol, 32, 109-128.

Clutter AC and Brascamp EW (1998). Genetics of performance traits, pp. 427-462 in The Genetics of the Pig, edited by Rothschild MF and Ruvinsky A. CAB International, Wallingford, UK.

Cohen P, Miyazaki M, Socci ND, Hagge-Greenberg A, Liedtke W, Soukas AA, Sharma R, Hudgins LC, Ntambi JM, Friedman JM (2002). Role for stearoyl-CoA desaturase-1 in leptin-mediated weight loss. Science, 297, 240-243.

de Koning DJ, Janss LLG, Rattink AP, van Oers PAM, de Vries BJ, Groenen MAM, van der Poel JJ, de Groot PN, Brascamp EW, van Arendonk JAM (1999). Detection of quantitative trait loci for backfat thickness and intramuscular fat content in pigs (sus scrofa). Genetics, 152, 1679-1690.

de Koning DJ, Rattink AP, Harlizius B, van Arendonk JAM, Brascamp EW, Groenen MAM (2000). Genome-wide scan for body composition in pigs reveals important role of imprinting. Proc Natl Acad Sci, 97, 7947-7950.

Delavaud C, Bocquier F, Chilliard Y, Keisker DH, Gertler A, Kann G (2000). Plasma leptin determination in ruminants: effect of nutritional status and body fatness on plasma leptin concentration assessed by a specific RIA in sheep. $J$ Endocrinol, 165, 519-526.

Demeure O, Renard C, Yerle M, Faraut T, Riquet J, Robic A, Schiex T, Rink A, Milan D (2003). Rearranged gene order between pig and human in a QTL region on SSC 7. Mamm Genome, 14, 71-80.

Ehrhardt RA, Slepetis RM, Siegal-Willot J, van Amburgh ME, Bell AW, Boisclair YR (2000). Development of a specific radioimmuno assay to measure physiological changes of circulating leptin in cattle and sheep. $J$ Endocrinol, 166, 519-528.

Enoch HG, Catala A, Strittmatter P (1976). Mechanism of rat microsomal stearoyl-CoA desaturase. J Biol Chem, 251, 5095-5103.

Evens GJ, Giuffra E, Sanchez A, Kerje S, Davalos G, Vidal O, Illan S, Noguera JL, Varona L, Velander I, Southwood OI, de Koning DJ, Haley CS, Plastow GS, Andersson L (2003). Identification of quantitative trait loci for production traits in commercial pig populations. Genetics, 164, 621-627. 
Gerbens F, van Erp AJM, Harders FL, Verburg FJ, Meuwissen THE, Veerkamp JH, te Pas MFW (1999). Effect of genetic variants of the heart fatty acid binding protein gene on intramuscular fat and performance traits in pigs. J Anim Sci, 77, 846-852.

Gerbens F, de Kong DJ, Harders F, Meuwissen THE, Janss LLG, Groenen MAM, Veerkamp JH, Van Arendonk JAM, te Pas MFW (2000). The effect of adipocyte and heart fatty acid-binding protein genes on intramuscular fat and backfat content in Meishan crossbred pigs. J Anim Sci, 78, 552-559.

Harlizius B, Rattink AP, de Koning DJ, Faivre M, Joosten RG, van Arendonk JAM, Groenen MAM (2000). The X chromosome harbors quantitative trait loci for backfat thickness and intramuscular fat content in pigs. Mamm Genome, 11, 800-802.

Jeon JT, Carlborg O, Tornsten A, Giuffra E, Amarger V, Chardon P, Andersson-Eklund L, Andersson K, Hansson I, Lundstrom K, Andersson L (1999). A paternally expressed QTL affecting skeletal and cardiac muscle mass in pigs maps to the IGF2 locus. Nat Genet, 21, 157-158.

Jiang ZH and Gibson JP (1999). Genetic polymorphisms in the leptin gene and their association with fatness in four pig breeds. Mamm Genome, 10, 191-193.

Kaestner KH, Ntambi JM, Kelly TJ, Lane MD (1989). Differentiation-induced gene expression in 3T3-L1 preadipocytes: a second differentially expressed gene encoding stearoyl-CoA desaturase. J Biol Chem, 264, 14755-14761.

Kennes YM, Murphy BD, Pothier F, Palin MF (2001). Characterization of swine leptin (LEP) polymorphisms and their association with production traits. Anim Genet, 32, 215-218.

King JA, Marker PC, Seung KJ, Kingsley DM (1994). BMP5 and the molecular, skeletal, and soft-tissue alterations in short ear mice. Dev Biol, 166, 112-122.

Knott SA, Marklund L, Haley CS, Andersson K, Davies W, Ellegren H, Fredholm M, Hansson I, Hoyheim B, Lundstrom K, Moller M, Andersson L (1998). Multiple marker mapping of quantitative trait loci in a cross between outbred wild boar and Large White pigs. Genetics, 149, 1069-1080.

Knott SA, Nystrom PE, Andersson-Eklund L, Stern S, Marklund L, Andersson L, 
Haley CS (2002). Approaches to interval mapping of QTL in a multigeneration pedigree: the example of porcine chromosome 4. Anim Genet, 33, 26-32.

Kramer JA, LeDeaux J, Butteiger D, Young T, Crankshaw C, Harlow H, Kier L, Bhat BG (2003). Transcription profiling in rat liver in response to dietary docosahexaenoic acid implicates stearoyl-coenzyme A desaturase as a nutritional target for lipid lowering. J Nutr, 133, 57-66.

Malek M, Dekkers JCM, Lee HK, Baas TJ, Rothschild MF (2001). A molecular genome scan analysis to identify chromosomal regions influencing economic traits in the pig. I. Growth and body composition. Mamm Genome, 12, 630-636.

Marklund L, Nystrom PE, Stern S, Andersson-Eklund L, Andersson L (1999). Confirmed quantitative trait loci for fatness and growth on pig chromosome 4. Heredity, 82, 134-141.

Marx J (2003). Cellular warriors at the battle of the bulge. Science, 299, 846-849.

McNeel RL, Ding ST, Smith EO, Mersmann HJ (2000). Effect of feed restriction on adipose tissue transcript concentrations in genetically lean and obese pigs. J Anim Sci, 78, 934-942.

Mihara K (1990). Structure and regulation of rat liver microsomal stearoyl-CoA desaturase gene. J Biochem, 108, 1022-1029.

Milan D, Bidanel JP, Iannuccelli N, Riquet J, Amigues Y, Gruand J, Roy PL, Renard C, Chevalet C (2002). Detection of quantitative trait loci for carcass composition traits in pigs. Genet Sel Evol, 34, 705-728.

Miyazaki M, Kim YC, Gray-Keller MP, Attie AD, Ntambi JM (2000). The biosynthesis of hepatic cholesterol esters and triglycerides is impaired in mice with a disruption of the gene for stearoyl-CoA desaturse 1. J Biol Chem, 275, 30132-30138.

Miyazaki M, Kim YC, Ntambi JM (2001). A lipogenic diet in mice with a disruption of the stearoyl-CoA desaturase 1 gene reveals a stringent requirement of endogenous monounsaturated fatty acids for triglyceride synthesis. $J$ Lipid Res, 42, 1018-1024.

Miyazaki M, Jacobson MJ, Man WC, Cohen P, Asilmaz E, Friedman JM, Ntambi JM 
(2003). Identification and characterization of murine SCD4, a novel heart-specific stearoyl-CoA desaturase isoform regulated by leptin and dietary factors. J Biol Chem, 278, 33904-33911.

Nagamine Y, Haley CS, Sewalem A, Visscher PM (2003). Quantitative trait loci variation for growth and obesity between and within lines of pigs (Sus scrofa). Genetics, 164, 629-635.

Nezer C, Moreau L, Brouwers B, Coppieters W, Detilleux J, Hanset R, Karim L, Kvasz A, Leroy P, Georges M (1999). An imprinted QTL with major effect on muscle mass and fat deposition maps to the IGF2 locus in pigs. Nat Genet, 21, 155-156.

Nezer C, Moreau L, Wagenaar D, Georges M (2002). Results of a whole genome scan targeting QTL for growth and carcass traits in a Pietrain $\times$ Large White intercross. Genet Sel Evol, 34, 371-387.

Nezer C, Collette C, Moreau L, Brouwers B, Kim JJ, Giuffra E, Buys N, Andersson L and Georges M (2003). Haplotype sharing refines the location of an imprinted quantitative trait locus with major effect on muscle mass to a 250-kb chromosome segment containing the porcine IGF2 gene. Genetics, 165, 277-285.

Ntambi JM, Buhrow SA, Kaestner KH, Christy RJ, Sibley E, Kelly TJ, Lane MD (1988). Differentiation-induced gene expression in 3T3-L1 preadipocytes: characterization of differentially expressed gene encoding stearoyl-CoA desaturase. J Biol Chem, 263, 17291-17300.

Ntambi JM (1999). Regulation of stearoyl-CoA desaturase by polyunsaturated fatty acids and cholesterol. J Lipid Res, 40, 1549-1558.

Ntambi JM, Miyazaki M, Stoehr JP, Lan H, Kendziorski CM, Yandell BS, Song Y, Cohen P, Friedman JM, Attie AD (2002). Loss of stearoyl-CoA desaturase protects mice against adiposity. Proc Natl Acad Sci, 99, 11482-11486.

Óvilo C, Perez-Enciso M, Barragan C, Clop A, Rodriguez C, Oliver MA, Toro MA, Noguera JL (2000). A QTL for intramuscular fat and backfat thickness is located on porcine chromosome 6. Mamm Genome, 11, 344-346.

Óvilo C, Oliver A, Noguera JL, Clop A, Barragan C, Varona L, Rodriguez C, Toro M, 
Sanchez A, Perez-Enciso M, Silio L (2002). Test for positional candidate genes for body composition on pig chromosome 6. Genet Sel Evol, 34, 465-479.

Perez-Enciso M, Clop A, Noguera JL, Óvilo C, Coll A, Folch JM, Babot D, Estany J, Oliver MA, Diaz I, Sanchez A (2000). A QTL on pig chromosome 4 affects fatty acid metabolism: Evidence from an Iberian by Landrace intercross. J Anim Sci, 78, 2525-2531.

Rattink AP, de Koning DJ, Faivre M, Harlizius B, van Arendonk JAM, Groenen MAM (2000). Fine mapping and imprinting analysis for fatness trait QTLs in pigs. Mamm Genome, 11, 656-661.

Rohrer GA and Keele JW (1998a). Identification of quantitative trait loci affecting carcass composition in swine: I. Fat deposition traits. J Anim Sci, 76, 2247-2254.

Rohrer GA and Keele JW (1998b). Identification of quantitative trait loci affecting carcass composition in swine: II. Muscling and wholescale product yield traits. $J$ Anim Sci, 76, 2255-2263.

Rohrer GA (2000). Identification of quantitative trait loci affecting birth characters and accumulation of backfat and weight in a Meishan-White composite resource population. J Anim Sci, 78, 2547-2553.

Ruiz-Cortes ZT, Men T, Palin MF, Downey BR, Lacroix DA, Murphy BD (2000). Porcine leptin receptor: molecular structure and expression in the ovary. $\mathrm{Mol}$ Reprod Dev, 56, 465-474.

Smith TPL, Showalter AD, Sloop KW, Rohrer GA, Fahrenkrug SC, Meier BC, Rhodes SJ (2001). Identification of porcine $L h x 3$ and SF1 as candidate genes for QTL affecting growth and reproduction traits in swine. Anim Genet, 32, 344-350.

Van Laere AS, Nguyen M, Braunschweig M, Nezer C, Collette C, Moreau L, Archibald AL, Haley CS, Buys N, Tally M, Andersson G, Georges M, Andersson L (2003). A regulatory mutation in IGF2 cause a major QTL effect on muscle growth in the pig. Nature, 425, 832-836.

Wada Y, Akita T, Awata T, Furukawa T, Sugai N, Inage Y, Ishii K, Ito Y, Kobayashi E, Kusumoto H, Matsumoto T, Mikawa S, Miyake M, Murase A, Shimanuki S, Sugiyama T, Uchida Y, Yanai S, Yasue H (2000). Quantitative trait loci (QTL) 
analysis in a Meishan $\times$ Gottingen cross population. Anim Genet, 31, 376-384.

Walling GA, Archibald AL, Cattermole JA, Downing AC, Finlayson HA, Nicholson D, Visscher PM, Walker CA, Haley CS (1998). Mapping of quantitative trait loci on porcine chromosome 4. Anim Genet, 29, 415-424.

Walling GA, Visscher PM, Andersson L, Rothschild MF, Wang LZ, Moser G, Groenen MAM, Bidanel JP, Cepica S, Archibald AL, Geldermann H, de Koning DJ, Milan D, Haley CS (2000). Combined analyses of data from quantitative trait loci mapping studies: Chromosome 4 effects on porcine growth and fatness. Genetics, 155, 1369-1378.

Wang L, Yu TP, Tuggle CK, Liu HC, Rothschild MF (1998). A direct search for quantitative trait loci on chromosomes 4 and 7 in pigs. J Anim Sci, 76, 2560-2567.

Ward RJ, Travers MT, Richards SE, Vernon RG, Salter AM, Buttery PJ, Barber MC (1998). Stearoyl-CoA desaturase mRNA is transcribed from a single gene in the ovine genome. Biochim Biophys Acta, 1391, 145-156.

Wimmers K, Murani E, Ponsuksili S, Yerle M, Schellander K (2002). Detection of quantitative trait loci for carcass traits in the pig by using AFLP. Mamm Genome, 13, 206-210.

Zhang L, Ge L, Parimoo S, Stenn K, Prouty SM (1999). Human stearoyl-CoA desaturse: alternative transcripts generated from a single gene by usage of tandem polyadenylation sites. Biochem J, 340, 255-264.

Zhang YY, Proenca R, Maffei M, Barone M, Leopold L, Friedman JM (1994). Positional cloning of the mouse obese gene and its human homolog. Nature, 372, 425-432.

Zheng Y, Prouty SM, Harmon A, Sundberg JP, Stenn K, Parimoo S (2001). Scd3-A novel gene of the stearoyl-CoA desaturase family with restricted expression in skin. Genomics, 71, 182-191. 
Assignment of the porcine stearoyl-CoA desaturase $(S C D)$ gene to $S S C 14 q 27$ by fluorescence in situ hybridization and by hybrid panel mapping

(Published in Animal Genetics) 
Isolation and molecular characterization of the porcine stearoyl-CoA desaturase (SCD) gene

(Accepted by GENE with revisions) 


\section{4}

SCD (stearoyl-CoA desaturase) gene variants and their association with fatness traits in pigs

(Submitted to Animal Genetics) 


\section{Summary}

Stearoyl-CoA desaturase $(S C D)$ is a rate-limiting enzyme in the biosynthesis of unsaturated fatty acids. So far the porcine $S C D$ gene has not been characterized. The isolation and molecular characterization of the full-length cDNA and genomic DNA sequence of the porcine SCD gene were described in the thesis. The 5134 bp cDNA contains a 1080 bp open reading frame encoding a protein of 359 amino acids with a calculated molecular mass of $41.3 \mathrm{kDa}$ and theoretical isoelectric point of 9.4. The porcine SCD shares high identity (>80\%) with the other mammalian SCD. To further elucidate the genomic structure of the porcine SCD gene, 20,985 bp of genomic DNA sequence was determined encompassing the complete porcine $S C D$ gene. Similar to the other mammalian orthologs, particularly in term of exon size and exon/intron boundary, the porcine $S C D$ gene spans a transcription unit of 16,186 bp, consisting of six exons with sizes ranging from 131 bp to 4048 bp, and five introns varying in size from 518 bp to 4784 bp. The unusual long 3' UTR of 3848 bp as opposed to the 176 bp 5' UTR appears in the last exon. A comparative analysis of different mammalian SCD promoters identified some regulatory domains required for the transcription regulation in the 5' flanking sequence of the porcine SCD gene, such as the conserved polyunsaturated fatty acid response region (PUFA-RE). Reverse transcription (RT)-PCR result indicates that the $S C D$ gene is expressed ubiquitously in pigs. The porcine $S C D$ gene was assigned to chromosome 14q27 by fluorescence in situ hybridization (FISH) and screening of hybrid panels with intronic primers. A total of 26 gene polymorphisms were revealed in the $21 \mathrm{~kb}$ DNA sequence, including 24 
single nucleotide polymorphisms (SNPs), a 24 bp length polymorphism in the fourth intron and a triplet nucleotide insertion in the fifth intron. None of SNPs lead to an amino acid exchange. Significant differences in allele frequencies of the SNP $\mathrm{T}(-233) \mathrm{C}$ and the SNP C(641)T (number refer to the corresponding position starting with +1 at the adenine of initiation codon ATG) were observed in samples of three Western commercial pig breeds (Landrace, Large White, and Duroc) and three Chinese indigenous pig breeds (Erhualian, Luchuan, and Huai). The Western pig breeds revealed higher frequencies of the allele $T$ at the SNP T(-233)C, whereas the Chinese pig breeds showed higher frequencies of the allele $T$ at the SNP C(641)T. Associations of SNPs $\mathrm{T}(-233) \mathrm{C}$ and $\mathrm{C}(641) \mathrm{T}$ with fatness traits have been investigated in $\mathrm{F}_{2}$ animals of a White Duroc $\times$ Erhualian pig resource family and a purebred White Duroc population. Significant associations were observed between the SNP C(641)T and backfat thickness at the $6-7^{\text {th }}$ rib, backfat thickness at the last rib, and the average backfat thickness at four points (at the shoulder, the $6-7^{\text {th }}$ rib, the last rib and the hip joint) in the $F_{2}$ resource family $(P<0.05)$. The allele $T$ has an unfavorable effect (i.e. positive) on backfat thickness. 


\section{Acknowledgements}

The author wishes to express his sincere gratitude to the following people who have dedicated their kindest help to my study and dissertation work. First of all, sincere appreciations are due to Prof. Dr. Dr. Bertram Brenig, dissertation director, and Prof. Dr. Dr. Lusheng Huang, co-director of dissertation. Their supervision and guidance in the past three years led me to the successful completion of all of the requirements of my PhD degree at the Faculty of Agriclture Sciences, Georg-August-University of Göttingen. Secondly, I am very indebted to Dr. Christoph Knorr for his kindness of providing me the convenience to knock his door at any time and help me to solve different problems during my research. I am also thankful to Prof. Dr. Henner Simianer for kindly being my co-examiner. Thanks Prof. Dr. Clemens Wollny, who accepts to be my third examiner.

The author wishes to thank Mrs Alexandra Deppe and Viola Raupach for their technical assistance along with my research. The thanks are also due to other graduate students at the Institute of Veterinary Medicine, Georg-August-University of Göttingen, Christian Beuermann, Jule Beck, Kirsten Bornemann-Kolatzki, Annette Muller, Kesinee Gatphayak, Leonard Bull for their assistance during my research.

I am very grateful to my good friends and colleagues at Jiangxi Agricultural University in my home country, Mr. Nengshui Ding, Huashui Ai, Yuanmei Guo, Congyin Chen, Junwu Ma, Mrs. Lihua Zhou and Lin Li for their encouragement during these three years of study and for their assistance during my research and preparing this thesis. Finally I would appreciate my family and my parents-in-laws for 
their forever support. They encourage me during my frustration and they feel proud for me during my success. My wife and loved son give me the inspiration to complete my study. My parents-in-laws help us take care of Gaofei. Without their support, I would never be able to complete this thesis.

Many thanks also to all the other colleagues in Goettingen and NanChang whom I didn’t listed in detail for all their kindly help in this dissertation work. 


\section{The Porcine SCD mRNA and DNA sequence}

LOCUS AY487829 5134 bp MRNA I i near MAM 07- JAN 2004

DEFI N TI ON Sus scr of a st ear oyl-COA desat ur ase ( SCD) mRNA, compl et e cods.

ACCESSI ON AY487829

VERSI ON

AY487829. 1 G : 40549307

KEYWORDS

SOURCE

Sus scr of a ( pi g)

ORGAN SM Sus scr of a

Eukar y ot a; Net azoa; Chor dat a; Cr ani at a; Ver t ebr at a; Eut el eost om ;

Nammal i a; Eut her i a; Cet ar t i odact yl a; Sui na; Sui dae; Sus.

REFERENCE 1 (bases 1 to 5134)

AUTHORS Ren, J., Knor r, C. , Huang, L. and Breni g, B.

TI TLE I sol at $i$ on and nol ecul ar characterization of the porcine st ear oyl-CoA desat ur ase ( SCD) gene

JOURNAL Unpubl i shed

REFERENCE 2 (bases 1 to 5134)

AUTHORS Ren, J., Knor $r, \mathrm{C}$. and Breni g, B.

TI TLE Di r ect Submissi on

JOURNAL Submitted (26- NOV-2003) I nst it ute of Veteri nary Medi ci ne,

Geor g- August- Uni ver si ty of Goett i ngen, Groner Landst r. 2, Goet t i ngen 37073, Ger many

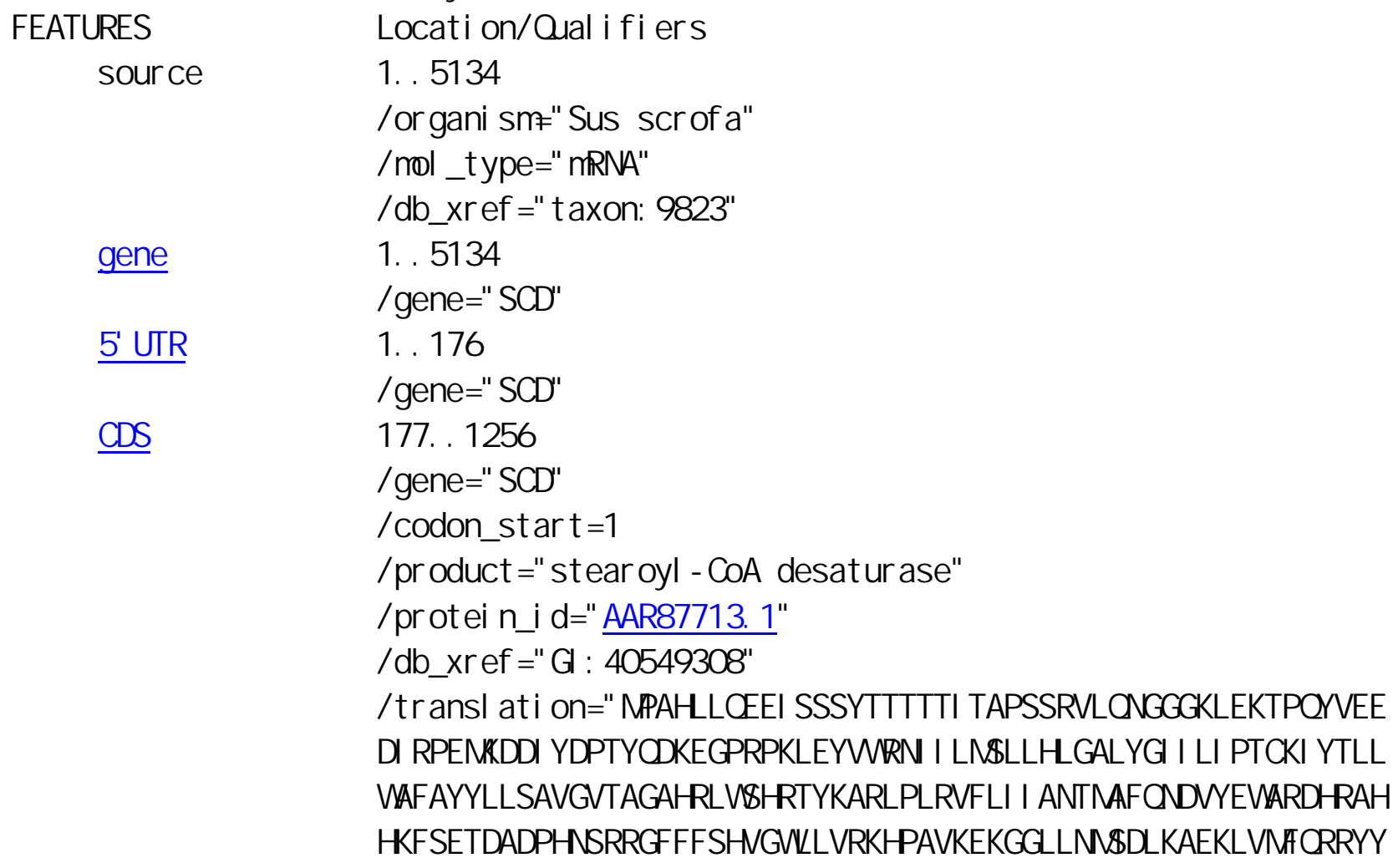


KPGI LLMCFI LPTI VPUYCWGEAFPQSLFVATFLRYAI VLNATWVVNSAAHLYGYRPY DKTI SPREN LVSLGAVGEGFHNYHHTFPYDYSASEYRWHI NLTTFFI DCNAALGLAY DRKKKVSKAAI LARI KRTGDESYKSG"

\begin{tabular}{|c|c|}
\hline vari at $i$ on & 299 \\
\hline & /gene=" SCD" \\
\hline & /r epl ace="t " \\
\hline 3' UTR & 1257. . 5134 \\
\hline & /gene=" SCD" \\
\hline vari at $i$ on & 3052 \\
\hline & /gene=" SCD" \\
\hline & /repl ace="t " \\
\hline vari at i on & 3251 \\
\hline & /gene=" SCD" \\
\hline & /repl ace="g" \\
\hline vari at $i$ on & 3257 \\
\hline & /gene=" SCD" \\
\hline & /repl ace="g" \\
\hline vari at i on & 3297 \\
\hline & /gene=" SCD" \\
\hline & /repl ace="c" \\
\hline pol yA_si gnal & 4857. . 4862 \\
\hline & /gene="SCD" \\
\hline pol yA_si gnal & 5086. . 5091 \\
\hline & /gene=" SCD" \\
\hline
\end{tabular}

\section{ORI GI N}

1 acagcaggt c gggt gcagac accgacccaa cgt gcagcaa agggt tccga gcgcagcat c 61 gct gat ct cc gcgcaagagc cggct ccagc act agt ct ac gct cagt gcg gt ct gccacg 121 aact cct ccc t gaagt ct ca t ccct gggaa agt gat ccca acgt ccgaga gcccagat gc 181 cggcccactt gct gcaagag gagat ct ct a gct cct acac aaccaccact accat cacag 241 cacct tcct c cagggt cct g cagaat ggag ggggcaagt t ggagaagact ccccaat acg 301 tggaagaaga cat ccgccct gaaat gaaag at gacat ct a tgacccaacc t accaggat a 361 aggagggccc aaggcccaag ct tgaat at g tt ggagaaa cat cat cct $c$ at gagt ct gc 421 tacact tggg agccct gt at gggat cat at t gat ccccac ct gcaagat a t acacct t gc 481 tct gggcgtt t gcct act at ct gct gagt g ct gt gggt gt cacggcagga gct caccgcc 541 tgt ggagt ca ccgaact tac aaagct cgac t gcccct gcg ggt ct tcctg at cat tgcca 601 acacgat ggc at tccagaat gacgttt atg aat gggcccg agatcaccgt gcccaccaca 661 agt tt caga aacagat gct gat ccccaca at cccgacg tggctttt c t ct ctcacg 721 tgggt ggct gct gt gcgc aaacacccag ccgt caaaga gaagggt ggt t gct taaca 781 tgt ct gacct aaaagccgag aagct ggt ga t gt tccagag gaggt act ac aaacccggt a 841 t cct gt tgat gt gct t cat c ct gcccacga t cgt gccet g gt at tgct gg ggt gaagct $t$ 901 tt ccccaaag cct gt tcgt c gccacct t tc t tcgt tacgc cat cgt gct c aat gccacct 961 ggct ggt aaa cagt gct gcc cacct at acg gat at cgccc t t at gacaag act at t agcc 1021 cccgggagaa tat cct ggt t t cat gggag ct gt gggt ga gggct t ccac aact accacc 1081 acacctttcc ct at gact at tctgccagcg agt accgctg gcacat caac t aaccacgt 
1141 t ct t cat cga ct gcat ggct gccet gggt c t ggct t at ga ccggaagaaa gt at ccaagg 1201 ct gccatct t ggccaggat $t$ aaaagaactg gagat gagag ct acaagagt ggct gagt t 1261 ggggt ccct $t$ gggt tcctt t tct gaaagcc agct gggcag aggt t aatg ttctgtt at 1321 taact act ga at aat gct ac caggat gct a aagat gat ga tgt aacccg t t ccagt aca 1381 gt at tcttt aaaat t ct t $t$ taagat ga aagcct acaa t tctgcct t at gat gct aa 1441 gct cat at t c ttgtt cttc tctctct ct agt cccattg tcct tctct ggct tgttc 1501 ct gt cacct t cct ct ct ct cccct cact gt gccccagg caaggagct g gt cagt cgt $t$ 1561 ggt gggt t c cagct tccaa agcct agacc tt tcagt agt ccaaaact gg t gagcggt ct 1621 ttgccccaga tagct ctttc tttgagttgt cctgagcttt aaggt gggt g gctcaaggga 1681 gagaggt gat aaaat ct ct gggaaagccc ct gttcat a ttttcagccc agact tt gc 1741 tcaat gacaa aaat aact ct at tt ggcac aaagct tcga aagcaggt aa ct tgt caggg 1801 gagggagt t a gcat gct gt g t gt ggt gggg t t gat aaaga agggggaggt gaggt gggaa 1861 accaggcagg aggct cctgc tgtgat ggga cactcggctg act gcccagt gagggctttg 1921 cgccct ggca cacagcat gc t tcct t ct c tcct gact ct ggggaat ggc cgt ggaact $t$ 1981 ggcaat gct a gaact caaaa gcacat ccca gt gt cccaat gt acgt tagg ct gaggat aa 2041 agaagcagca tttagtt gt ggcagcagtg gt ctct gctg gggaagaagt ct t cttgt c 2101 t ct t t aat aa caggaagat $t$ t ct tat t cca t agagt gaga aat ct gagg t tct t tccgg 2161 aat gct gaa tcggcaact $c$ at ggaat tgt cct cact ct t t cat ct t cc cgct ct gcca 2221 tct t gggat acagct cccc tcat agt aac aat aaggt gg ct gccgcat t t gagacat c 2281 ggaact gagg t gt gt ggt g gt accgt ggt gagct taact at ct tcccaa aaagaaagga 2341 tt t agcagg tggaggt ggg t cccacat aa agat agt t aa acct cggt ac t t gct gga 2401 at accaacat aat tct cttg gact at t tcc ct ct gaaaga gaaggaggct t gagaagagg 2461 aagaat gggg gt ggat ggt c tcct t cct c t ct ct gct ga acaggagat g gaggggt ga 2521 ggggcagggt ct agaggcag ctcct gagac at aacat tgc aaacgaaggg ct ct ggggga 2581 t t cagaaggt tact gagt aa gt tact ggac gt cct cct at gggaagct gg t cacacaggc 2641 aagt t agat a ttggggt tca tt tcat t cat tccagt gct gct ggaat a aggaact aga 2701 aggct gct cc ccacagt gt g aagcct t c act cct gcct tct agcct ca agcgt act ac 2761 cct gact at g gat tcct gct ct gccet gt c t at ccgttt t t cctgccgg t t ct at ct cc 2821 tccct gaggt ttttcctttc tct gragg gcaggcct cc tttgggagt a tgcaaaggca 2881 gt gat ggct g ct gct ct aca ggcagct tcc t ct cccacag tcagaat gct cagggt cact 2941 gaaccact gt t tct ct cac aaaggt gagc tagct gccac ct ccacgt gg cctccagagt 3001 ct ccacct gc accettgtgc tccct gcca ct ccaat gat tcaagacaag gcgggcaaac 3061 cct cct agaa acat cccggg cacgggcat c ctttct cat a aggcacagcc aagccaaatg 3121 ct cacgt gt gccagt gagt cagccacaga gcaaaagagg gtt gt ggt t agt ct cct ct 3181 at ct gggt ca gaaccagaga gcaggct gga t gcccct gc tt gct cggt a agcct gccca 3241 gcct gagt ca at gct cacgg ct gacagt gc aat gct tgca gaaacaggag ggagcct ggt 3301 ct tcact ggg aagcacaaga ggccaagaca agt tccaaag tgcctcact c gaaagggaac 3361 cct gt cccct ggagct aggg t gt accacaa agctttggct gagt ct ggg ct gaacagcg 3421 t ct ct gt ca gcaaact aac cagcat tccc t acagcacag cccaaggcag acaagagaat 3481 agaagagggc tggaaaacaa aaaat aagaa cct tggccca ct cct gt ccc t gt aacct ca 3541 gt cgt caaca cagaagcct g gcttt act ct aaagat gga aat acaat accagat gct 3601 ct gt ccactg ttgagcccca ggagt ggaag ggcagagagc at t ct tcct gt at taactg 3661 agt aaat gga ggat aaaggg gt gggct gg act agaggca tct t gt ct t t gagccat $t$ 3721 ct tct cagt a gaaaaaaag ctgat ggaag at cactgt ag ttcacat tcc cagacccaag 
3781 cacct act ct $t$ tggaaat ga ct gt t gggt t agt t t t aat $t$ ccacaggt cg tcagat gcct 3841 gct t t at agc tgat gat caa aaccaact tt tatct t tct a t tct aat tgt tt caat gga 3901 tct gat ccat accat aaccc t acacaaggc tggat ggggt tct t aggcca agggccccag $3961 \mathrm{tgt}$ at gt gt g gat gt gt agg gt gggagggc ggggagt aag gaat act t t t t t caaggt t c 4021 t aaagct gaa ttcaaat gac gcat taat ga cccagaaact cagat ct gat agaat ct gaa $4081 \mathrm{tttct}$ aacag gcct gctt t gt aggt gt ac tgacaact t a tct gggggcc t t acat ct t $4141 \mathrm{tt}$ t aat cggt gt tacgt ccg agcct gct ct gct ccct cac tccctct gca ct ccctct gt 4201 ggcgt tccct t gcccct gag agcct gcaga agt ggct ggt agaagt gggg ggct ggct gg 4261 agaat tat ca gt at gcagga t tcct t tctg ggctt tgtt t tggaaact t cct tagggct 4321 gtttt at ta agt gcccaca tttgacggaa ggt ggaagga att gaat gt at t gattta 4381 t aat gt tat $t$ at tat at t $t t t t$ agat ta aaagat ggt $t$ gt agcat t t a aaacggaaac $4441 \mathrm{cttttctcct}$ ggt tagct ag tatcct gagt gt at tct ct g taagt gt agc t caaat gggt 4501 cagcgt gaag aaaagt t aaa gaaagcacga tgt caaggt t acacgggt gg t t aaggccag 4561 ggcct ct cct accact gt gc cact gact tg ct at gt gacc ct gggcaagt cat t taact a 4621 taat gt gcct cagt tt tcct $t$ ct gt t aaaa t gggat aat a at act gacct acct caaagg 4681 gcagt tt ga ggcgt gact a at gct tttt a taaagcat t t tgggat cct t cagcagagga 4741 at tct ct taa gtcct gagt a $t \mathrm{ttt}$ tat aat aacagt at cc accat gaact gt gtccacca 4801 tgaaccct gt gtcct ggat g ct gt cat t aa tct tt at ggt tct ctct gag aaat tgaat a 4861 aacccaat ag at aagt ggt g gat aact agt cagacagaat ct gagaat gc at aaact cat 4921 tgccat ggaa acat acacag gat accttt cct tgat tgg gt gggat tt t t ccccttt 4981 t at gt gggat agt agt t at $t$ tgt ggcct aa gaat aat tt ggaat aat $t \mathrm{t} c t$ at taat at 5041 caact ct gaa gct agt t gt a ct gat ct gag at gt gtt tg tt cat aat aa aagggaagt g 5101 aat caaaaaa aaaaaaaaaa aaaaaaaaaa aaaa 
LOCUS AY487830 20985 bp DNA I i near MAM 07- JAN 2004

DEFI N TI ON Sus scr of a st ear oyl-COA desat ur ase ( SCD) gene, exons 1 through 6 and compl et e cds.

\begin{tabular}{|c|c|}
\hline ACCESSI ON & AY487830 \\
\hline VERSI ON & AY487830. 1 G : 40549309 \\
\hline KEYWORDS & . \\
\hline SOURCE & Sus scr of a ( pi g) \\
\hline
\end{tabular}

ORGAN SM SUs scr of a

Eukar yot a; Net azoa; Chor dat a; Cr ani at a; Ver t ebr at a; Eut el eost om ; Nammal i a; Eut her i a; Cet art i odactyl a; Sui na; Sui dae; Sus.

REFERENCE 1 (bases 1 to 20985)

AUTHORS Ren, J., Knor r, C., Huang, L. and Breni g, B.

TI TLE I sol at $i$ on and mol ecul ar characterizat $i$ on of the porcine st ear oyl - CoA desat ur ase ( SCD) gene

JOURNAL Unpubl i shed

REFERENCE 2 (bases 1 to 20985)

AUTHORS Ren, J., Knor $r, \mathrm{C}$. and Breni g, B.

TI TLE Di rect Submissi on

JOURNAL Submitted (26- NOV-2003) I nst i tute of Vet er i nary Medi ci ne, Georg- August- Uni ver si ty of Goet ti ngen, Groner Landst r. 2, Goet t i ngen 37073, Ger many

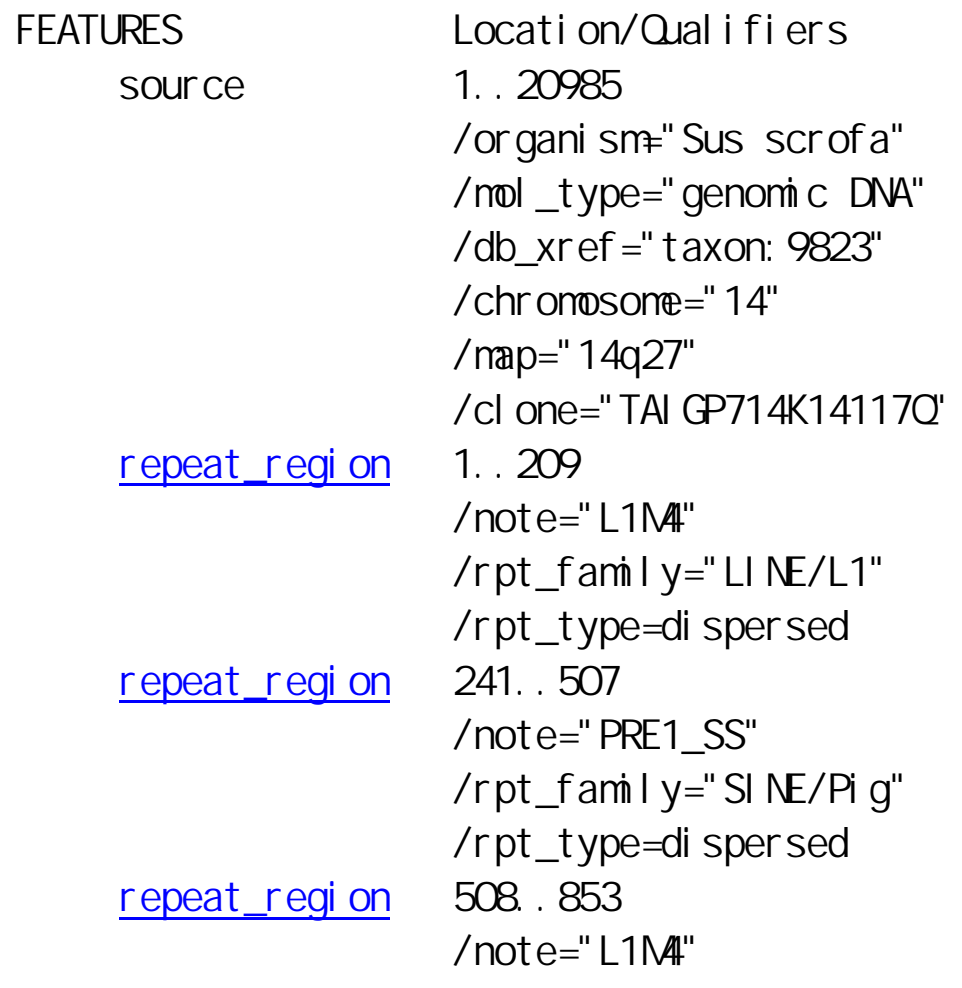




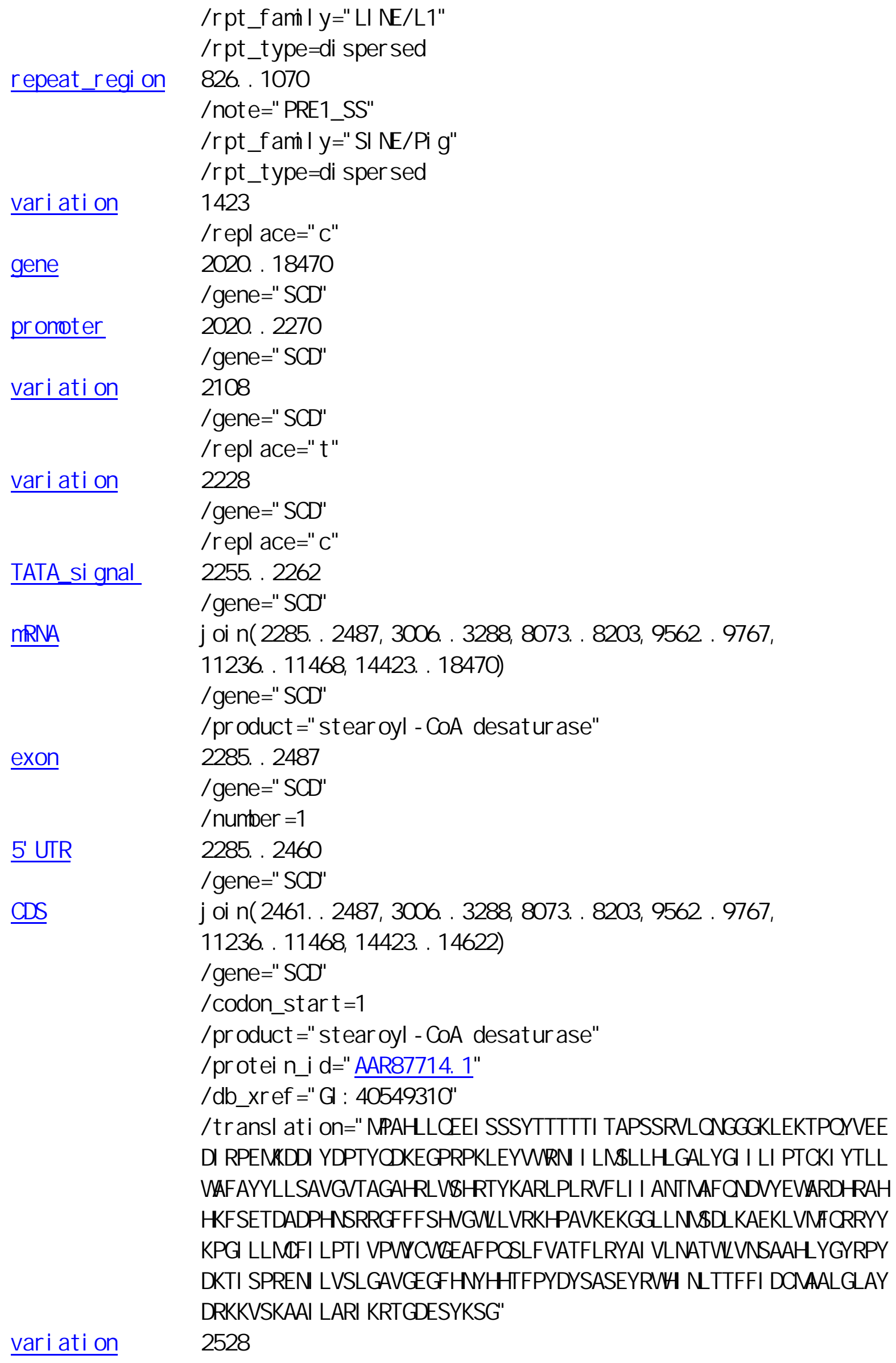




\begin{tabular}{|c|c|}
\hline & /gene=" SCD" \\
\hline & /repl ace="g" \\
\hline var i at i on & 2650 \\
\hline & /gene=" SCD" \\
\hline & /repl ace="c" \\
\hline var i at i on & 2894 \\
\hline & /gene=" SCD" \\
\hline & /repl ace="a" \\
\hline exon & 3006. . 3288 \\
\hline & /gene=" SCD" \\
\hline & /number $=2$ \\
\hline var i at i on & 3101 \\
\hline & /gene=" SCD" \\
\hline & /repl ace="t " \\
\hline vari at i on & 3534 \\
\hline & /gene=" SCD" \\
\hline & /repl ace="a" \\
\hline repeat_regi on & 4869. . 4944 \\
\hline & /not e="L3b" \\
\hline & /rpt_f ami I y="LI NE/CR1" \\
\hline & $/$ rpt_t ype=di sper sed \\
\hline repeat_regi on & 5739. . 5953 \\
\hline & /not e="PRE1_SS" \\
\hline & /rpt_f ami l y="SI NE/Pi g" \\
\hline & $/$ rpt_type=di sper sed \\
\hline repeat_regi on & 6808. . 7068 \\
\hline & /not e="PRE1_SS" \\
\hline & /rpt_f ami I y="SI NE/Pi g" \\
\hline & $/$ rpt_t ype=di sper sed \\
\hline repeat_regi on & 7071.7145 \\
\hline & /not e="M R" \\
\hline & /rpt_f ami I y="SI NE/M R" \\
\hline & $/$ rpt_t ype=di sper sed \\
\hline repeat_regi on & 7188. . 7440 \\
\hline & /not e="PRE1_SS" \\
\hline & /rpt_f ami I y="SI NE/Pi g" \\
\hline & $/$ rpt_type=di sper sed \\
\hline repeat_regi on & 7571.7598 \\
\hline & $\begin{array}{l}\text { /not e="I ow compl exi ty GC ri ch regi on" } \\
\text { /rpt_type=di sper sed }\end{array}$ \\
\hline exon & 8073. . 8203 \\
\hline & /gene=" SCD" \\
\hline & /nunber $=3$ \\
\hline repeat_regi on & 8619. . 8771 \\
\hline
\end{tabular}




\begin{tabular}{|c|c|}
\hline & $/$ not e="M R" \\
\hline & /rpt_f ami I y="SI NE/M R" \\
\hline & $/$ rpt_t ype=di spersed \\
\hline vari at i on & 9261 \\
\hline & /gene=" SCD" \\
\hline & /repl ace="g" \\
\hline exon & 9562. . 9767 \\
\hline & /gene=" SCD" \\
\hline & $/$ number $=4$ \\
\hline vari at i on & 10188 \\
\hline & /gene=" SCD" \\
\hline & /repl ace="t " \\
\hline vari at i on & 10216. . 10221 \\
\hline & /gene=" SCD" \\
\hline & /repl ace=" agct $t$ aggaat ccact $t$ aggaat ct $t \mathrm{t}$ gt a" \\
\hline vari at i on & 10246 \\
\hline & /gene=" SCD" \\
\hline & /repl ace="c" \\
\hline vari at i on & 10447 \\
\hline & /gene=" SCD" \\
\hline & /repl ace="a" \\
\hline vari at i on & 10498 \\
\hline & /gene=" SCD" \\
\hline & /repl ace="g" \\
\hline vari at i on & 10542 \\
\hline & /gene="SCD" \\
\hline & /repl ace="g" \\
\hline vari at i on & 10551 \\
\hline & /gene=" SCD" \\
\hline & /repl ace="c" \\
\hline variation & 10552 \\
\hline & /gene=" SCD" \\
\hline & /repl ace="a" \\
\hline var i at i on & 10601 \\
\hline & /gene=" SCD" \\
\hline & /repl ace="a" \\
\hline repeat_regi on & 10940. . 11101 \\
\hline & /not e="M R" \\
\hline & /rpt_f ami I y="SI NE/M R" \\
\hline & $/$ rpt_type=di sper sed \\
\hline exon & 11236. . 11468 \\
\hline & /gene=" SCD" \\
\hline & /nunber $=5$ \\
\hline var i at i on & 11754 \\
\hline
\end{tabular}




\begin{tabular}{|c|c|}
\hline & /gene=" SCD" \\
\hline & /repl ace="g" \\
\hline repeat_regi on & 12562. . 12783 \\
\hline & /not e="PRE1_SS" \\
\hline & /rpt_f ami l y="SI NE/Pi g" \\
\hline & $/$ rpt_t ype=di sper sed \\
\hline vari at i on & 13756. . 13758 \\
\hline & /gene="SCD" \\
\hline & /r epl ace="ct cct c" \\
\hline vari at i on & 14416 \\
\hline & /gene="SCD" \\
\hline & /repl ace="g" \\
\hline exon & 14423. . 18470 \\
\hline & /gene=" SCD" \\
\hline & $/$ nunber $=6$ \\
\hline 3' UTR & 14623. . 18470 \\
\hline & /gene=" SCD" \\
\hline repeat_regi on & 15468. . 15646 \\
\hline & /not e="MLT1L" \\
\hline & /rpt_f ami I y="LTR/MaLR" \\
\hline & $/$ rpt_type=di spersed \\
\hline vari at i on & 16418 \\
\hline & /gene=" SCD" \\
\hline & $/$ repl ace="t " \\
\hline vari at i on & 16617 \\
\hline & /gene=" SCD" \\
\hline & /repl ace="g" \\
\hline var i at i on & 16623 \\
\hline & /gene="SCD" \\
\hline & /repl ace="g" \\
\hline variation & 16663 \\
\hline & /gene=" SCD" \\
\hline & /repl ace="c" \\
\hline repeat_regi on & 17742. . 17779 \\
\hline & $\begin{array}{l}\text { /not e="I ow compl exi ty AT ri ch regi on" } \\
\text { /rpt_type=di sper sed }\end{array}$ \\
\hline repeat_regi on & 17941. . 18032 \\
\hline & /not e=" MON1" \\
\hline & /rpt_f ami I y="SI NE/Monot r enes" \\
\hline & $/$ rpt_t ype=di sper sed \\
\hline pol yA_si gnal & 18223. . 18228 \\
\hline & /gene="SCD" \\
\hline pol yA_si gnal & 18452. . 18457 \\
\hline & /gene=" SCD" \\
\hline
\end{tabular}




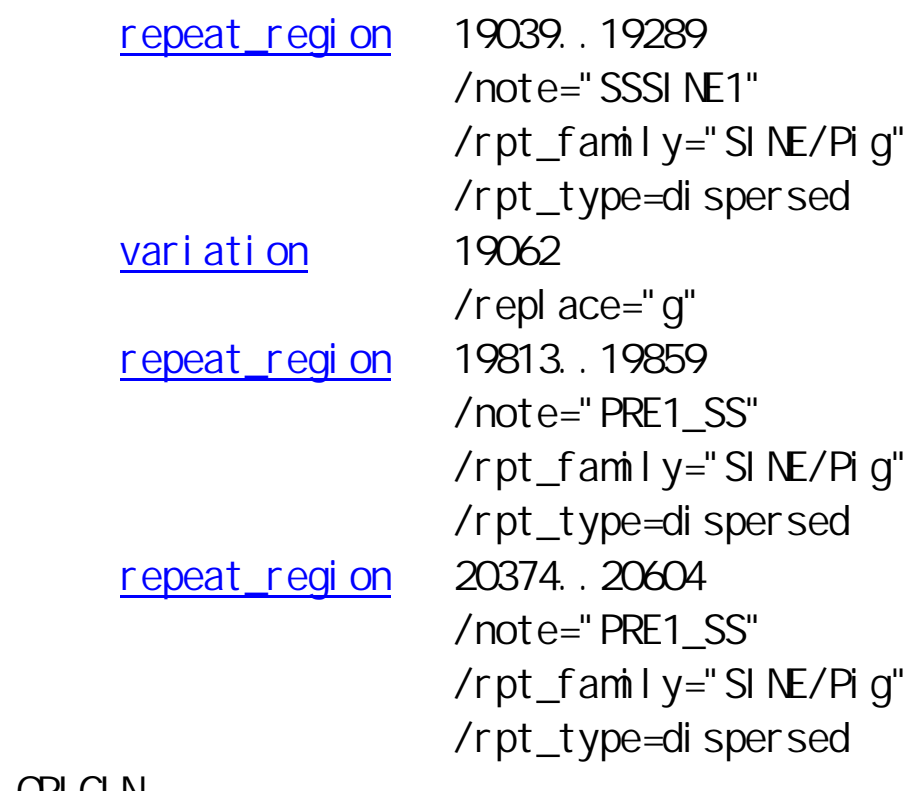

1 tct agaccct ttgaat ttcc actt aaat tt tagaat ct gc t gt ct at t cct caaagaa 61 at ct gt gga $t$ tt ct at agt gat t aaat ta at ct at agat caacact gag t ct gt ccat $t$ 121 tat gaacaca gaat at aaca aat ctttt $t$ tctct ct at $t$ taagagt t t aaagttt t 181 ct cagcat $\mathrm{g}$ ttt gat act t t cagt gt ag ct at cct at a aacat t aga $t$ t t at tct t 241 gt gacattt t gat gt ct t t aattttg tttttt agg gccgcacctg tggcacat ga 301 agt tcct ggg ccaggggt cg aat cagagcc aaagct acca gcct at acca ccaccat agc 361 aacgccaggt ct ggaccgca tct gt gat gt acgccggagc tcgt gacaat gccagat cct 421 t aacccact g agcaaggcca gcat gt aacc cacaacct cg tggacact ag t cgagt t ct t 481 aacccgct ga gccacaagga gaact ccat $t$ t t gat gct a $t t t t$ aaacag $t$ at at $t t t$ aa 541 at t cat ct gcaat gtt $t$ ttaat agaa $t$ at aggacag aat aat t t t $t$ t at act ggt 601 ttct at ct g acctt tctaa at cact tac caattt gac act ttttgg tggt agat tc 661 tat acattt t tcat acacac agt aggt ct tct gcaaat a at aacagt t ct t ct ct $t$ 721 ttcctatct $t$ at at ctttc attctttt tcctgtccat cat gcaacct aggatttcta 781 gcacaat gt $t$ gact agaaat ggt agacgat $t$ at at gct tg cct gt ct ct taaggggaaa 841 ttttttttt tttttttgg tcttttaag cctgcaccca tggct aggaa ct gt agct gc 901 tggcct at gc cacagccaca gcaacact gg at ccgaact g tat ct gt gac ct acaccaca 961 gct cat ggct at gccagat c ct taacccac t gagcgaggc cagggat cga accct cgacc 1021 tcacggttcc tagt cggat t cgtctccgct gcgccacaac gggaact ccc acgact aatg 1081 at t aagt aaa at gat t cttg tggact gact t gcct aat aa t t ct at agct gat agct at $t$ $1141 \mathrm{tt}$ t gt cccac ttacaagt cc ttttgcct gc ttctggat ga aggcacacgc tgcgct tcct 1201 cccttttct c atgaaagcca ttccaaaat t acaact cgac aat ctgaaga at t ccaaaa 1261 cat cccgcac acgttcgggg t ggggggggg gcgt gggcac aaggacggga tcgct cact g 1321 gt gcct ggcg gcgaacgt cc cct gct gggc t t gcct agt a gct gaacgcc gt gcgcgcgt 1381 gcaggt ccac acat ct at ct at gcat ct ac gt gt gt gt ac acggct gccg gcct ggagac 1441 cggcgagt tc agcagt acgc at ct at cgcc ccgccgccag tgggcggcgc agagccattg 1501 ttccgccgcc ggccgaccct cagcccct gc ggcacgcgcg ttcgt cacgg agggaggt gg 1561 ggct tcgccg ggcccccggc ccccaacccg gggtt gaag gcacgt ct cc ccct cccacg 1621 cgt ct ccgcg agct agaagg cgggagt gga gt t gt gcgt a gcggt cgccc gcgcggct t c 1681 acccacact t tcccoggaaa ct tccct agt gcccat cctt tcgcgaagtg ccccagggcc 
1741 agt cct gggc t agcacccac ct cccacccc cct act gagt cct ct tcct c t t ccagggaa 1801 gacgct ctcg agcgcctccg aggaggcagg acgccgggca gaagcccagc ggccggt gga 1861 agagaagct g aggaggagaa agggagggga gggggagt ga ggagct cgcg gcagagggaa 1921 cagcagat tg cgccgagcca at ggcaacgg caggacgagg tggcaccaaa tt cccttcgg 1981 ccaat gacgc gccagagt ct acagaagccc at tagcattt ccccaggggc aggggcagag 2041 gcaggggct g cggagaccga gccgcggagt gt ct gcagca tccagt tt t gcgtctccgg 2101 cccccagcaa gccccggct c tct gt ct cct cccct ct ccc gcccat gcgg tt ct cccacg 2161 gt gagccaac $t$ ct gcgcact $t$ tgcccct tc $t$ tggcagcga at aaaagggg tcagaggaaa 2221 t acaggat ac ggt cgcccac tgccagct ct agcctt t aaa t acccagcct ggggagaccc 2281 acgcacagca ggt cgggt gc agacaccgac ccaacgt gca gcaaagggt t ccgagcgcag 2341 cat cgct gat ct ccgcgcaa gagccggct c cagcact agt ct acgct cag tgcggt ct gc 2401 cacgaact cc t ccct gaagt ct cat ccctg ggaaagt gat cccaacgt cc gagagcccag 2461 at gccggccc act gct gca agaggaggt g agt tt ccaag taat ggcccc cagaccgcgg 2521 gct cgccagt gct ggt tggg ct tct aggt g act cggt gt a gaagagagt t gagat cgccg 2581 aggacagcca cctttttcga gt tgt at agt ct tcagt t t $\mathrm{ttgggaat}$ gt ggat tgt aat $2641 \mathrm{ttgggaactt}$ agt tct ccaa ct tt tgt t tc ct aaagct t c aaagaaaaat ct ggt ggt ac $2701 \mathrm{ctgt}$ accct g atgt gt gt ag gcat gcgggc tt tcct t tgt gt gt t gaag gggt gcgagt 2761 gt tt t acccc tct at t t ccc ct tcccct ga ggt t caccc t cct ccccaa t t t ct ccgca 2821 cagt tcct gg ggact tgcgt ct ct tccat c t aggat agac ct gccct ca ggt aacct gg 2881 gt at tggggc caggt ct gt g cct at acccc gccct t cccc cagct agacc agggagt gaa 2941 gt ggcccct a gt gt ct ccac gt gt cct ccc ct ct ct ccca gct ct gcact tccact ct ct $3001 \mathrm{tt}$ cagatct c tagct cct ac acaaccacca ct accat cac agcacct tcc tccagggt cc 3061 tgcagaat gg agggggcaag t t ggagaaga ct ccccaat a cgt ggaagaa gacat ccgcc 3121 ct gaaat gaa agat gacat c tat gacccaa cct accagga taaggagggc ccaaggccca 3181 agct tgaat a tgt t ggaga aacat cat cc tcat gagt ct gct acact t g ggagccct gt 3241 at gggat cat at gat cccc acct gcaaga tat acacct t gct ct ggggt aagaggt ccc $3301 \mathrm{cttgt} c c t c c$ tgt ct cagt a tcccaggt tc tct ccact ct $\mathrm{ttt}$ aat acag tagcaact ta 3361 cacagagt ag aaacaccagc ccct ccaggc cgaggttttt ccaaccat t ct ct taggt g 3421 t t gt ggt ggg ct gggaaggg agt ct agggg gt t t gggat g caggagt gt c gat tct gggg 3481 cct t t aat t t gggggggggg t ggagaggg agccct ggga ccat gggcca caggctt tga 3541 agt gagt aga tct gt gccag ggagt cagct $t \mathrm{ttctgtttc}$ aagt cat tt t ct tgact gct 3601 tgt cccagcc ct gccagcct agaaagaatc aaggccctt a cct ggat gca tgggaacat g 3661 gggct agact agt gt gact t t agagggcac at gct gggt a t agt cacggg gt agcaagag 3721 aaact act ca ggaagagggt t aagcagaag aggggggaag agagct gt gg tcatccat ga 3781 aat tattt g ccct gat cct tagcct tat $c$ aggct cct t a at t acacaga cagaggaagg 3841 cggct cct gc at aact cat g tt acat ggat gt ct tgct ct gt gact ccac gt gggt ct cc 3901 agggaact gc acat gccact caagaaaatg ttct aat gaa at aaggt t aa agaaacgt t t 3961 cct gccccat tccccaccca tcct gct cca gcccct ct cc cct gat gcca ggagt gcct c 4021 ct tgct gggg acagccaagc cagaaaagag act ccggagc agccccggcc ct caggct gc 4081 tgcagt gagg gagacagt cc cccgt gcgt c cct gacct gc cct t agct ca gct ct t t cag 4141 gaat ccat gg ct gggct ga tagt ggagcc ct gccccct c acacacat gc gct ct gcagg 4201 cat tgccact cct gcct cga gt ct gact tg ggaagaggag agcagggaac tct aaagat $c$ 4261 caggagct cc at gct gct ac cctct gt gat gggt gt gggg t tcagaact c cct gt tcaga 4321 aagccacggt at ggt t tct g gagcagt gt c ggat gt t ggg tcct gct gg cagct at gct 
4381 ct ggagggt ggt t ct acag aaggact ggt gggccaagt t tcagcaaagt cct ccaggac 4441 ct ct t gat c t aaagagggt ggat ct ggt c tgcggagcct tgt ct ggca gat cct ct $\mathrm{g}$ 4501 gt gccacaga cagagaaat g cat ct gggt a gat tccct ct ct caat t t c ccagacacaa 4561 act ggggaca acaggactt t ttt aagct t agaaaggt ag tgctcctct t t ggcct ccc 4621 tgaagcat gt ggagt gccg gaccggggat cagacct aag cct cagct gc aggaat gccg 4681 gat cct taac ccaccct acc aggccgggat tccacct gag tcccagcat t cccaaggt gc 4741 cgct gat ccc gt gt gct ac agcggacat t ccaagaaagg tgct cct gga gt tcct cgag 4801 tgt cat gct ggggccagcc aggt gcagag gaaat caat t cat cct caga ccaggaaggg $4861 \mathrm{ct}$ ct t at aat t gt aagggga gggggact t c t gctccccag cccct ct gag aacccagcag 4921 agct gagt t gcagt gt gag gaat caagag ccagggacat ggat gcccca gggaat ct gt 4981 gggct cccct cct gacccet tctcccccat agaggagt ct tcacaagt t agtcact $\mathrm{cc}$ 5041 aagt ccccct ccagcct cag gact ccct gt cggcctcgtt aagt tccgag tt ggccagg 5101 cagct gct gc tggct ct tct ccct ggctg ct act gcagg ggacaggat g ct gt ccccaa 5161 ccaaggct gt gcct gccgcc tttt ggt gc cct gcct gt a gat gt gt gct ct gccet gg 5221 acagaaacct gt cacacaga ct ggat ggtg act tttt tac t gt ccct gg at cct gt ggt 5281 ggt ggat ggc $t$ tagct gat g gaat gaccat $t$ t tggt at gg ccat at ccga gct cct ct gg 5341 tggagt tggg gggagggt ca gagt tcccga acctt aagag t tcaggaact tggct tcat c 5401 tt t t ct tgt c t tgt ccct aa ggacagt gct gaat tagcaa at ggt gt ga t t ccagcat $t$ 5461 tgt caggact gagcaat tt $t$ gagt gt ct ca gaagagccct gagggct gaa gcgat acct g 5521 gcagcacct g ggggct ct ga ggcgaaacgt ct ccaggct c ttccttaggg ct aaaact at 5581 gaagt tt gc ttaaccat aa at ct agact t tagt agagaa tgaat at cca act gacaggc 5641 tt aggggt gc t ggt agaaaa aggcaccaga gact gggtg tt tccccagg t t ct ct gt $\mathrm{a}$ 5701 ggat cat at g tgct tccat $t$ ttgtgcttt gct tttttag ggccacact $t$ gcggcat at g 5761 taagt t ccca ggct aggggt caaat gggag ct gcagt tgc tggcct acac cacagccaca 5821 gcaact ccca cgt acaccac agt tcat ggc aat gct agat ct t aaccca ct gagt gagg 5881 ccaggcat ca cacccat gt c ct cat ggat a ct agt caggt t cgt aat t ca ct gagccaca 5941 gt cagaact g cct gcgt gt g ct tt ct gagt cagct gcca gggt ct tcgg ttgcat gt aa 6001 ccaccccagt agcttcctgg gttct gagct acctctttcg tgctcaaaga ct tt ct tgg 6061 cctttggt ga ttggcgggct gcggct caac tgt tat t at ccaggt gcag at gcaggcag 6121 at gct gcct c t gggaggat a tt accacaag gcgggggagg ccagaaaat c acct ggaccc 6181 ct aat gcagc cccgaggacc gt gggt ggca ct tccct gag acagact ct g gct ccct ggc 6241 tct cct ccct gtcct gt agg aggaat aggc t agggt agag gaaggt gggt gggacagggg 6301 gct gt tt ag gaaact ggt g t ctgtggctg agaacacaag acaat gt gt t acaat gt gt g 6361 gt gt ct ccaa ct gcaact aa gt tcagt ggc cactgaggat ccat tgt t t c tagct gct t c 6421 cct aggaat g aaacat tgt c aacagt cact gct ct cccaa ggcct cagcc t ct gcct cct 6481 agagct gct g aacagaggaa ggt gggt gtg cccagcaacc cgcctcccag tt agagact c 6541 caacct gcac ccct agaacc t gcaggcccc caggaagatg aggt agacag cgct ggggt g 6601 cccccacca cagct ttgag cctgccct ac cgttgcct ag aat taaccct gacgggggt a 6661 tgagct gact gaggaaggt g gcaaaggaga gat gcaggag cgct gcgagt at ct gggcg 6721 gggggggcat ggt aaacat c ct cgagccag ggctcaggag caccaagt ac t t gt gacag 6781 aacacctcat ttcaaaccat ggctccatt ttttttttt tttcctttg ctttttaggg 6841 ccacacct t c ggcat at gga ggt tcccagg ct aggggt ct aat cagagct gt agccaccc 6901 acct acacca cagccat agg aact caggat ccgagccgca tct gcgacct at t ccat agc 6961 tcact gcaac gccagat cct taact cactg agt gat ccca gggat cgaac at gcaacct c 
7021 at ggt act a gttggat tag tttttgctgc gccacaacag gaact cct at ggct ccctt 7081 ct t act agcc at gt ggcct $t$ agat aaacac t t aat ct t t c tgagt gt ct a t t tct t ggc $7141 \mathrm{tt}$ aaacccca t gcaaggt at ccagt gaat c aaagaat aca gaaat ct gga gt t cccct t a 7201 tgt ct cagcc gt aacgaacc tgact agt at ccat aaggac tcgggt gat ccct ggaccc 7261 gct cagt ggg tt aaat at cc agcat tcctg t aagct gt gg t gt gggt t gc agacacagct 7321 ggggt ct ggc gt ggct gt gg cgt acgt tgg cggct gt ggc t ccaat t cca cccct agcct 7381 gggagct tcc at at gct ggg gat gt ggct c tagaaacaaa cacaaacaaa caaacaaaaa 7441 tcct ggcaa agct taagac tgtgcagat a tgactt aggt gcaaggcgag ttt tccccat 7501 t ct gt gacca cgcagt ct gc caaaagactg aaatggtttt gt accagat g gt aaat agct 7561 ct agt tet ga gcccccccc cgccccccgc t gccccccat gt cccct aga acccagagt c 7621 cct caaact g gt cagt gccc aggccat cct gt ct tacat a t tt t aat act gccct tgttt 7681 at gggt ct tc agct ct gcaa gagt act ctg t ggtcct t aa aact gt ggag aagct tagt g 7741 aaggt cagag gagat gggac ct gggat aat gt cct tcat g acagagaat g acaagt ggct 7801 ggagggt gag agccct ct c $\mathrm{t}$ ct gt cccgc ct tcct gaac tt tctgggac ct gt aagct $t$ 7861 at tccagctg tgaggct aag aggat aggag gcgat ggt aa tttttttcca agt ggt aaaa 7921 tt gaagggga ct aagagat c taggt gt ccg tggagt tcag ggaaaagcag at cct cacct 7981 gcagcct gaa ggacacct ag acgct gacct gaggagaaca tcacgt gt aa gact tgcccc 8041 gat t act gac t ccct gt cct gt ct tccggc agcgt t gcc t act at ct gc t gagt gct gt 8101 gggt gt cacg gcaggagct c accgcct gt g gagt caccga act t acaaag ct cgact gcc 8161 cct gcgggt c t tcct gat ca t gccaacac gat ggcat t c caggt aagaa gccagct gt g 8221 ct cagct ct t tat caaacgc aggcgat ggg tgcctggaag ggagcagcac ct ggacagct 8281 act tcact t t cct ct ct gct tccagt cacc t caagt t cag gt t cagt cct t gggt ccat a 8341 acacct gcag tact t ggag t gact ggaaa agggaaat ag gggat aaaga ggaaat agcc 8401 t ct gt gt at a ggat cgt t t t cgagcct ccg $t$ t gt cacaca gt ct ggt cgt t gt ggt ccct 8461 tcat t agt gc acgaggcagg aact gaccct gat t tcct ag gcagccgt tg gacaat acat 8521 t cact at t t aggt gaacat ctcaggact c caccaaaagg gat taaagt $t$ aat gt t cac 8581 agat t cat ga accct at tgt $t$ t t caggt ga gaagat caaa cact t t t at a gt gt t aact a 8641 tacct cct gg ccct at tctg agcact tgac aaggat taca ccat taagcc ct cccaacag 8701 tct taggagg ttggt actgt t gt gat cccc at t tcacgga gggggaagct gt gt cact ga 8761 gggt gt aggt agaccat cat t at ggt cctg t gt tgagct g ccaagct gt c t aagt caaat 8821 at tgaggt ct gct gaagccg gaagct cat a gcagggaat $t$ ggagaaaggg aact ccgagt 8881 t at gaacag cagcact ggg caaaggct ag cat gt tgt gt ggggct tagc ttggat caag 8941 gggcaaaaag aaggaaacca aatcggt tcc tt tct tcgt g gcagt gt ct c acacagct gc 9001 at aact gt ct t ct gccat ag cact taacgc ct gaaggcc cct gat gt gg t ccct gt gg 9061 ggcaaaagaa ggaagagat a ttggcaccct ct ctaagcga tagaaagt gt cccagaggag 9121 cccagagacc at t ggaaat gcggt caaat cat gat tatg tgt ctggcct tgt gagt tg 9181 tgggagct ga atct gccaa gggat t aggc agcct gt gaa gaccct t gc tccagt tct $t$ 9241 gct ggaagaa $t$ tgcaat tt t acctcct agt gaaact ct t c aagct ct at a caat ccat ct 9301 ccat t ct gcc caccat at aa cccgcaagaa gcagccagcc ct at tcat gt ggt cct gaga 9361 ct gaaggt g cttttccact taagcat cag tggccagt a gagaggaggc aact ccct ga 9421 ct cct ccttt ggagccct ga ct cccaggt a tttcgcgagc tt gggct gag cgcct cgggc 9481 tct gaagac acct agccat tggcat t ccc ct gagagggt gt ct ct cct c aggcctccat 9541 t cct ct t ct c t gt ccct cca gaat gacgt t t at gaat ggg cccgagat ca ccgt gcccac 9601 cacaagt tt cagaaacaga tgct gat ccc cacaat t ccc gacgtggct t t t ct tct ct 
9661 cacgt gggt t ggct gct tgt gcgcaaacac ccagccgt ca aagagaaggg tggt t gct 9721 aacat gtctg acct aaaagc cgagaagctg gt gat gt tcc agaggaggt g agt gct gt gg 9781 tggt ggagct gggcgcctgg tgtt gggga caccct ct cc cctccctgt t tt tcttcta 9841 ggact tgt cc acat aagct g ggaact gac agggt ct gcc tacccaaat cat aat caa 9901 aaccct tctt ttat gggcca cagccat aga ctgttgt ga ttctttct ct ct gagct aaa 9961 aaaaaaacca gt aaggt ca acaat gt gtg ttgacctgt t acagt cat gg at acaaagct 10021 acat gt tgcc at agt cctt a ccttcaagaa gt tcat agcc tgt ggggat gggagcact a 10081 agccaggt gt ccaaat acct at gacat ggc aaat at tt t t ct cccca ggaaaggcac 10141 agaggggagg gagact gt gg agt ggggaac at t agagaag ggt t t agga gaaggt agct 10201 t aggaat cca ct ggt ggat a gagat t t ca caagt gt tgg cggaggggga ggcagt gcaa 10261 acagaaagaa tgagct aaag cat gaagcat gt ccagcaa tagagt ccct ct gct taaag 10321 t acagggt gt ggt aggaaat aaagact aga gagaccgaga cct t tct gt ggggcct taa 10381 gagcagacag ggt t aat t c aact ccagca at aggaaacc at ggaagggt ttt gagccg 10441 gaat gt ggt c agaggt gt gc tct ggagagg tcaccct gca gat aggt gaa agaaaccat $t$ 10501 gggct gaaga ggt gagct gc agggccccag gt gaggaggt act gggcat c t gt gct gggg 10561 aagt ggt ggc acggagagga ggcgaaat gt ggggacacac gt gat ccaag agt agcagac 10621 tt gact gct g aagaggt gca ggaaat cagc tccct cggaa tgt cagt agc ct gt tt t act 10681 tt gggagaat gaagaat ggg ccagggcct c cagagggaca gcct gcaggc at ccgggaca 10741 ct cggt gt gc ccct gagggg aaaagaagag aaaggat cag aaggct gct ggct agcaag 10801 agaggaaggc aagat accaa acacagat t c tgcaaagagc act gacacca agagaggagc 10861 aggcagaat g gaaagacct g ggcaggagaa ct cagt tcag t aat ct gt aa t t gggccgc 10921 ccct gt tgt g gt acgat tag gct gt ggt ca aagagagcaa t ggat ggaga gt cgggagac 10981 aaggcat tcc agccet gct ccact ggt t c ct ggt ggt at gaccct agaa aagt cat t a 11041 gccct cct $t$ acct tacct c atcaaaaaag tat gat aat a acactgcct t ct caaaagac 11101 tacccaccc at ccct cttg ct ct gt t t cc tgccaccttg tgct cacagc gt agagggt a 11161 ggggacagct cagccccat g aaaggacaaa gt cagagt cc cct ccat gaa t ggggt gt gt 11221 gat ct ct ccc t gt aggt act acaaacccgg t at cctgt g at gt gct t ca t cct gcccac 11281 gat cgt gccc t ggt at gct ggggt gaagc ttt tccccaa agcctgt tcg t cgccacct $t$ 11341 tct tcgtt ac gccat cgt gc t caat gccac ct ggct ggt a aacagt gct g cccacct at a 11401 cggat at cgc cct tat gaca agact at t ag cccccgggag aat at cct gg t t cat ggg 11461 agct gt gggt aagt tagcag tccat agcaa gaccccat ct agt gggct gc tggt taagag 11521 t at tagact a ggagccagaa aaaccagat $t$ aacctgctt t at gacccct c tctgtt tct c 11581 tgct at aaaa ct aaggt gca at agt agat a cccct gaga gt gggcagc aagt ct t at a 11641 taaagagaat tgggct aaaa aat aacaat g t ct ct gagt c caggt t ccaa aaagat cccc 11701 aggt gct ct gat gaggaac cgctttggct tgtcctttt ccagt cat ct ct gagct ggc 11761 acat ggt ct g gct aggggca gggact gcat gaat agaaca gt agggt ct t ct gggt ggcc 11821 agt aagcct a gtgttt at a tttagacatg ct at acaaaa tgcagaacaa at cct taaca $11881 \mathrm{tttcaacaag}$ ct ctct tt $\mathrm{t}$ at cacct tgc tat at caga gaggct gaac tcaaagt gt a 11941 tt tcat gcct tat gtttgg tgat gccaac at gaaggacc tcaaagcaac tgt ggt ggc 12001 ccttt tat ca ccgccgaccg ct ct cat ct c t gtccttta t tct tctct gt cctttat 12061 ct tct ct aac ccgt gct ggg aacacccgct cccct taaca tggct ggag aact cct gat 12121 aaagcagt t a at t gat cac aagt ct ct gc tcact gat ct aat gct gact at tcaagaat 12181 at ct t t ct aa aaaaaaaaa agt tat at $\mathrm{ttct}$ ct cat $\mathrm{t}$ ccagt gcaa tagccagaat 12241 ct aagacaac agt gt tctac cat ctgtct c cottt tatt t t cccctgc cact ct t t c 
12301 aact aaacat agat ct gac taacgcctgg aagcagttt cct aagcag cgcct gt gac 12361 ct ct t ccacg ccagt gat ca gt gccact gg t t gt ct ggca t at ct aggca acct ccct gc 12421 tccccacat g tgt gt acact gcggcct agc ttttgctttg ttct ct t aa aacct t ct $t$ 12481 t at gt gct ca accet gagca tcttttttt tacaat ct gt act aaagaca tt tcat t gt 12541 at ctttttt ttttttttt tagt gccgca cctgtgccat at ggaagt t c ccaggct agg 12601 ggt ccaat cc gagct acagc t gct ggcctc caccacagcc acggcaat gc cagat ccaag 12661 caacct acac cacagct cat ggcaat gct g gat cct taac ccact gagca aggccaggga 12721 tt gaacccac aacct cat gg ttcct agt tg gat t gtttt tgct gagcca caaggggaac 12781 tcct gt at ct ctttt taact ttcat gt at c t ccccct cc t t cagggac cct ct accat 12841 tgt gcat gt a tct act ct ga accat gtttg aaat ct aaca ggct at tt t c at agat t at 12901 gaat gt gcg gaagt t t ct g gaat gagact ggt cct ggat t t agaat gag ct cccccaac 12961 cccagt ct ct $t$ t ct aaccat ccgt t caaag tagct gccaa cat ct t cct t t gt ct caat $t$ 13021 at cat t cat c cct ccat cct ggct gct ct c ccctt at t a cct caccet t t gt t ct ccca 13081 tagct ggct $t$ ccctgt cat $t$ ct aat ct t t t t ct ct gaa t t acct cccc cacagt caca 13141 tgct cat ct c t ccgct aaag ct gacct cct gcct gagcc tct cct ggac t gt gt ct gc 13201 tgcccagt $t$ gcagagt ct $t$ gt cct tct cc tctttttt c tccct ggca act agt gt gt 13261 gt ct gat t aa agt t t t aaat ct gat aagt a t at ct gat aa gcct ggct ag t gct t at caa 13321 gat cct agct gcagaat tt $t$ at ggaaat $t c$ gt act t t tag cct ggggt $t$ at cct accct 13381 cct act cagt tcacact aga taagct gat $t$ at ccact gg tagagagt ca gacagaggac 13441 ct acct cgaa t gat gccctg gat ggt gt ca tttcctt gc agaat t cct tcct gct g 13501 tt at taat gt cat tact act ct actaaggc tct t cat ct tcaaagggct caacat gct c $13561 \mathrm{ttttat}$ agc tat tet gcc cagct ct gcc tgggcgt cat aaggggt cag cat gt cat a 13621 gt gaat gct gt tcggaaaa aagat cccgc caagggt gg agacct ct gg ct ct ggagt $t$ 13681 tgcacagct c aact cat gac agacat tat $t$ ct gaatccag agt ttctctg at t t ct tct 13741 at ggagcaaa gt gaact ct $t$ ct cagaagca tagaggttt t t at tct aat t ct aagcct $t$ 13801 tt gat t ct gt t t ccct caga gagct tct gt ct tat cagct tgacccccac accaggat c 13861 aagct caaag aat tagaagc cagagcagt c ccctct gaac cagt ggaaac tgaggaaat g 13921 tgggcccct g gt ct gggcct ct t ct gact tt gact gt t ggt gcct gat t ccgt ggt ac 13981 ct tct gccet t agagat ggt at ggt acagt ggggaaaggt at accccet $t$ gct cacct $t$ 14041 ttcagaaaca cggcagcagt tctt gt tct agact ct tct ctcctcaccc taacacat gc 14101 t cact cat ac agagct t taa ggt ct cagac caat aact ag tgaagct ctg gaat t ccca 14161 at ct aaaat $t$ t at cccct gt gat agcagt t t ct ct ccggt cat ct t at cc cct cagagga 14221 act gt cagt c ctct cccac agaggct ccc agagagccat ggcgaccagg gt gt ccccag 14281 t tgt t t ct t a aggt gcct ct gaggggat ct at t agt ga aaagact gga t t cat t cat $t$ 14341 caaccacagc aagt t at ct g ct aggt t ga gct gt gccac ccccagt gt a gct t cat gac 14401 ttt ct ct gc tttt attcc aggt gagggc ttccacaact accaccacac ct t ccct at 14461 gact at tct g ccagcgagt a ccgct ggcac at caact t aa ccacgt t ct t cat cgact gc 14521 at ggct gccc tgggt ct ggc tt at gaccgg aagaaagt at ccaaggct gc cat ct ggcc 14581 aggat t aaaa gaact ggaga t gagagct ac aagagt ggct gagt t gggg tccct gggt 14641 tccttttctg aaagccagct gggcagaggt ttaatgt tct gt t at taac tact gaat aa 14701 tgct accagg at gct aaaga tgat gat gtt aacccgttcc agt acagt at tct tt taaaa 14761 tt tct tt aa gat gaaagc ct acaat tct gcctt tat ga tgct aagct c at at t ct gt $14821 \mathrm{ttct}$ ctct $\mathrm{c}$ tct tct agt c ccat gt cct tct ct ggct ttgt tcct gt cacct tcct c 14881 t ct ct t cccc ct cact gt gc cccaggcaag gagct ggt ca gt cgt tggt g ggt t t ccagc 
14941 ttccaaagcc t agacct tt c agt agt ccaa aact ggt gag cggt ct t gc cccagat agc 15001 tctttctttg agt gt cctg agcttt aagg tgggt ggct c aagggagaga ggt gat aaaa 15061 tct ct ggga aagcccctgt tcat tat t t cagcccagac ttt gct caa tgacaaaaat 15121 aact ct at t t tggcacaaag cttcgaaagc aggt aacttg tcaggggagg gagt tagcat 15181 gct gt gt gt g gt ggggt tga t aaagaaggg ggaggt gagg t gggaaacca ggcaggaggc 15241 tcctgctgt g at gggacact cggct gactg cccagt gagg gct t gcgcc ct ggcacaca 15301 gcat gct tcc tt tct ct cct gact ct gggg aat ggccgt g gaact ggca at gct agaac 15361 tcaaaagcac at cccagt gt cccaat gt ac gt t aggct ga ggat aaagaa gcagcat t $a$ 15421 gt t t gt ggca gcagt ggt ct ct gct gggga agaagt ct t t ct tgt ct ct t t aat aacagg 15481 aagat ttct t at tccat aga gt gagaaat c ttgaggt tct ttccggaat $t$ gct gaat cgg 15541 caact cat gg aat gt cctc actcttttca tct tcccgct ct gccat ct t tgggat acag 15601 ct cccct cat agt aacaat a aggt ggct gc cgcat t t ga gacat cggaa ct gaggt gt g 15661 tt ggt ggt ac cgt ggt gagc t taact at ct tcccaaaag aaaggat t t agcaggt gga 15721 ggt gggt ccc acat aaagat agt taaacct cggt act t $\mathrm{g}$ ct tggaat ac caacat aat $t$ 15781 ct ct ggact at t tccctct gaaagagaag gaggct gag aagaggaaga at gggggt gg 15841 at ggt ct cct t tcct ct ct c t gct gaacag gagat ggagg ggt gagggg cagggt ct ag 15901 aggcagct cc t gagacat aa cat gcaaac gaagggct ct gggggat t ca gaaggt t act 15961 gagt aagt t a ct ggacgt cc tcct at ggga agct ggt cac acaggcaagt t agat at gg 16021 ggt tcat t c at cat tcca gt gct gct ggaat aagga act agaaggc tgct ccccac 16081 agt gt gaaag cctt tcact c ct gcct t ct a gcctcaagcg tact accctg act at ggat $t$ 16141 cct gct ct gc cct gt ct at c cgtttttcc tgccggt tct at ct cctccc tgaggtttt 16201 cct t t ct ct c t ggagggcag gcct cctttg ggagt at gca aaggcagt ga t ggct gct gc 16261 t ct acaggca gct tcct ct c ccacagt cag aat gct cagg gt cact gaac cact gt t ct 16321 ct tcacaaag gt gagct agc tgccacct cc acgt ggcctc cagagt ct cc acct gcaccc 16381 tt gt gct ccc ctgccactcc aat gat tcaa gacaaggcgg gcaaaccct c ct agaaacat 16441 cccgggcacg ggcat ccttt ct cat aaggc acagccaagc caat gct ca cgt tgt gcca 16501 gt gagt cagc cacagagcaa aagagggt tt gt ggt t agt c t cct ct at ct gggt cagaac 16561 cagagagcag gct ggat gcc ccct gct tgc tcggt aagcc t gcccagcct gagt caat gc 16621 t cacggct ga cagt gcaat g ct tgcagaaa caggagggag cct ggt ct t c act gggaagc 16681 acaagaggcc aagacaagt t ccaaagt gcc tcact cgaaa gggaaccct g t cccctggag 16741 ct agggt gt a ccacaaagct tt ggct gagt ct gggct ga acagcgt ct c t gt t cagcaa 16801 act aaccagc at ccct aca gcacagccca aggcagacaa gagaat agaa gagggct gga 16861 aaacaaaaaa taagaacct t ggcccact cc tgt ccct gt a acct cagt cg t caacacaga 16921 agcct ggct t tact ct aaag at ggaaat a tacaat acca gat gct ct gt ccact gt ga 16981 gccccaggag t ggaagggca gagagcat t $t$ ct cct gt at t aact gagt a aat ggaggat 17041 aaaggggt tg ggct ggact a gaggcat ct t t gt ct t t ga gccat t ct t c t cagt agaaa 17101 aaaaagct ga tggaagat ca ct gt agt t ca cat tcccaga cccaagcacc t act ctttgg 17161 aaat gact gt tgggt tagt $t$ t aat tccac aggtcgt cag at gcct gct $t$ t at agct gat 17221 gat caaaacc aacttttat c tttctat ct aat gttttc aat ggatctg at ccat acca 17281 t aaccct aca caaggct gga t ggggt t ct t aggccaaggg ccccagt gt a t gt gt ggat g 17341 tgt agggt gg gagggcgggg agt aaggaat act tttttca aggt tct aaa gct gaat tca 17401 aat gacgcat $t$ aat gaccca gaact caga t ct gat agaa tct gaat t $\mathrm{c}$ t aacaggcct 17461 tgct t gt ag gt gt act gac aact tat ctg ggggcct tac atct tt tt t a at cggt gt t a 17521 cgt ccgagcc tgct ct gct c cct cact ccc tct gcact cc ct ct gt ggcg t tccct gcc 
17581 cct gagagcc t gcagaagt g gct ggt agaa gt ggggggct ggct ggagaa t t at cagt at 17641 gcaggat tcc $t$ ttct gggct $t$ gt $t$ t gga aact t cct $t$ agggct gt t $t$ t at t aagt g 17701 cccacatttg acggaaggt g gaaggaat $t \mathrm{t}$ gaat gt at $t \mathrm{t}$ gat t tat aat gt tat tat $\mathrm{a}$ $17761 \mathrm{ttat}$ ttttt agat taaaag at ggt gt ag catt aaaac ggaaacct t t ctcctggt 17821 agct agt at c ct gagt gt at t ct ct gt aag t gt agct caa at gggt cagc gt gaagaaaa 17881 gt t aaagaaa gcacgat gt c aaggt tacac gggt ggt taa ggccagggcc t ct cct acca 17941 ct gt gccact gact gct at gt gaccct gg gcaagt cat t taact at aat gt gcctcagt $18001 \mathrm{tttccttctg} \mathrm{ttaaa}$ agg at aat ac tgacct acct caaagggcag ttttgaggcg 18061 tgact aat gc $t$ tt t t at aaa gcat tt ggg at cct tcagc agaggaat t c t ct taagt cc 18121 tgagt at t t $t$ at aat aaca gt at ccacca t gaact gt gt ccaccat gaa ccct gt gt cc 18181 tggat gct gt cat taat ct t tat ggt t ct c t ctgagaaat tgaat aaacc caat agat aa 18241 gt ggt ggat a act agt caga cagaat ct ga gaat gcat aa act cat tgcc at ggaaacat 18301 acacaggat a ccttttcct $t$ gat gggt gg gatttttcc cctttt at g t gggat agt a 18361 gttat ttgtg gcct aagaat aattt ggaa taatt t ct at t aat at caac t ct gaagct a 18421 gt t gt act ga t ct gagattg t gtt tgt t ca t aat aaaagg gaagt gaat c t gat gcct $t$ 18481 gt gt ct gaga ggt t t t t gc ct gt gagt ca gt ct ct t ggg act t aat ct g ccaccct at g 18541 t cct gt tcct gt acct t taa gagagt aaaa aaagt agaag ct acaat ggt tgat t cacac 18601 t ct agt aacc cgccct gccc tccct gccct tct taggggt aact t taggt t aaact cagc 18661 ct ggcagca ggaagccagg agt ct gct gc cat tagat ca gacat gt t aa ccccagct gg 18721 ct ct t t ggcc ct ggggaaat gccaggt ct c tttcggt aac at gggccaaa at gat act ga 18781 gagaggaaag gagcagcagg tgacact tcc ct ggaaaggg gt t ct gt acc t ggcaaccca 18841 ggct gggcca tcct gct t ca t t cct ct gaa at gt agcccc t tct gggaat aaagt ggct $t$ 18901 cct gaaaat g ctgat taaca acagcaggaa gaaaggaaaa gcaatcct ag agaagccttg 18961 t aaat tcct g gaat agagag ggct tcat ga tcat caact a gaaaggct t $\mathrm{ggct} t \mathrm{t}$ act 19021 gctttagct a agaatcttt tttttttt tttttttt gtcttttgc tattct tg 19081 ggt cgct cct gcagcat at g gaggt tccca ggct aggggt ccacagcaac gcgggat ccg 19141 agccgcgt ct gcaacct aca ccacagct ca cagcaacacc agat cct taa cccact gagc 19201 aggggcaggg accgaacccc caacct catg at cct agt c ggat tcgttg accactgcgc 19261 cacgacggga act cagct aa gaat ct t gat gt gcaaacga gaagggct t t t t t gaagag 19321 gct tcattt ccaacaggag ccacct aagc ttctgagcat tcccagacc cccccct tac 19381 act ttct agt gt aacgt cgc cctcaccttg gacaagcacg act ctcagt g at tcatccca 19441 aat caagt ct at at cagtg aggccttgcc aggcct taat aacgt aaat $t$ gat ggt ggca 19501 ct ttct taat at ct ggcttt ctacccett ccctctattg tgtt aaaat gttcgggttg 19561 gaccat tt t $\mathrm{ccat} t \mathrm{t}$ at a t aat ggcat g gt ccgccca agt ct ct gt t $t$ t ggaggca 19621 aagacat cag ccacat gaga aagggcagct gt gat aaact at agt gagt c t aggat gat a 19681 ct cat gaaac caaat t cct $t$ ggaacaat ct at at cagat a gagggat tgg gaccat gcgt 19741 caacagaaat ctcacaccct ctttttttt ctttcttt ttggtcgcac at gcagcaca 19801 ttgaagt tcc t at gt gacct at gccacagc tagggcaatg t ggat cct t aacccact gt 19861 gccacagcag gaact cgct a tgacaacatt tggt gcagga aacccaaat t gt gagt ccac 19921 cagact caat aacat t t act at aaacagcc at gt agt ga gt gct gaca gt gcat t at c 19981 acagcat t t c caaagcaggt gccat cat t a ccct aat tt t at gat gaaa t tccct agaa 20041 gagaaagaac acaaggcgag ggagt at gca aggat gct gt gat tcagct c agaactt tgc 20101 t t at t t act g ct ct ccaaat gggt gt aaag tagat aagca act t gat aag t ct ggat gca 20161 taagt cccat at at gt aagt agat gcctgg cgat at tcag t t at gct cag aggt aaaact 
20221 tggt agcaat ggt acagagc $t \mathrm{t}$ agt t t atg caaagt caaa t cgcagat gt gt cct ct gt t 20281 ccagaggaac ccaact cact ccacctcccg acatgt tt t a acat tcaacc acacctgagt $20341 \mathrm{tt}$ t aaagct c t cagaccat a gaaaccat t $\mathrm{ct}$ gggecgc t cccacggca t at ggaggt t 20401 cccaggct ag gggt cgaat c ggagct gt ag ccaccagcct acgccacagc cacagcaat g 20461 tgggat ccga gcct cat ct g caacct acac cacagct cac ggcaat gct g gat cct t aac 20521 ccact gagca aggccaggga t cgaacccgc aaact cat gg ttcct agt ca gat t t gt t aa 20581 ccact gagcc at gat gggaa ct cct cct ct at cgttt gc aaaccat act ccat ccaccc 20641 tgct ct tgt g ttt gagat c $t t t$ aagggca $t c t c t t c t t t ~ t a g a a a t g t c t c c t$ gcccct 20701 aat ggat cag tgct t aat aa aagt at gaa agacctcgtt tct agt tt t a aat tct gt ct $20761 \mathrm{ct}$ gt gacaaa ct gt gt gaaa tgt cacaggg agt gggaat t gcat tct gt g acct gt agt t 20821 aact tact aa act gcaggca aaaagccgat tcctgcat gc tgactt tggg gcaaat acca 20881 caagct ct aa t tgcaggt tc caagaagt tg agat tct at a ct gggat tgc ccct cccccg 20941 cccggggcct gcccagcctg ct gcaaccca ggccacagag agct c 


\section{List of publications}

1. Yan XM, Ren J, Guo YM, Ding NS, Chen KF, Gao J, Ai HS, Chen CY, Ma JW, Huang LS (2003). Research on the genetic variations of a1-fucosytransferase (FUT1) gene in 26 pig breeds. Yi Chuan Xue Bao, 30, 830-834 (PMID: 14577374).

2. Wang WJ, Huang LS, Gao J, Ding NS, Chen KF, Ren J, Luo M (2003). Polymorphism of growth hormone gene in 12 pig breeds and its relationship with pig growth and carcass traits. Asian-Australasian Journal of Animal Science, 16, 161-164.

3. Ren J, Huang LS, Evens G, Ai HS, Gao J, Chen KF, Ding NS (2003). AFLP markers for genomic DNA fingerprinting in pigs. Chinese Journal of Agricultural Biotechnology (Accepted).

4. Huang LS, Ma JW, Ren J, Ding NS, Guo YM, Ai HS, Li L, Zhou LH, Chen CY (2003). Genetic variations of the porcine PRKAG3 gene in Chinese indigenous pig breeds. Genetic Selection and Evolution (Accepted).

5. Yan XM, Ren J, Huang LS, Ai HS, Ding NS, Gao J, Guo YM, Chen CY, Ma JW, Shu QL (2003). Genetic variations analysis and characterization of the fifth intron of the porcine NRAMP1 gene. Asian-Australasian Journal of Animal Science (Submitted).

6. Huang LS, Deng SH, Gao J, Ren J, Chen KF, Ding NS, Ai HS, Evans G, Plastow G (2003). Initial characterisation of coat colour genes in Chinese pigs. Animal Genetics (Submitted).

7. Wang WJ, Huang LS, Chen KF, Gao J, Ren J, Ai HS, Lin WH (2002). Polymorphism of insulin-like growth factor-I gene in 13 pig breeds and its relationship with pig growth and carcass traits. Asian-Australasian Journal of Animal Science, 15, 1391-1394

8. Ren J, Huang LS, Ai HS, Gary E, Gao J, Chen KF, Ding NS, Deng SH (2002). 
Studies of population genetic relationships among 24 Chinese and exotic pig breeds using AFLP analysis. Yi Chuan Xue Bao, 29, 774-781 (PMID: 12561223, Article in Chinese).

9. Wang WJ, Chen KF, Ren J, Ding NS, Lin WH, Gao J, Ai HS, Huang LS (2002). Relationship of growth hormone (GH2) genotypes with some production performances in pig. Yi Chuan Xue Bao, 29, 111-114 (PMID: 11901991, Article in Chinese).

10. Lin WH, Huang LS, Ren J, Deng SH, Wang WJ, Liu BS, Zhou LH, Chen CY (2002). Research on genetic variation of heart fatty acid-binding protein gene in ten pig breeds. Yi Chuan Xue Bao, 29, 12-15 (PMID: 11838368, Article in Chinese). 


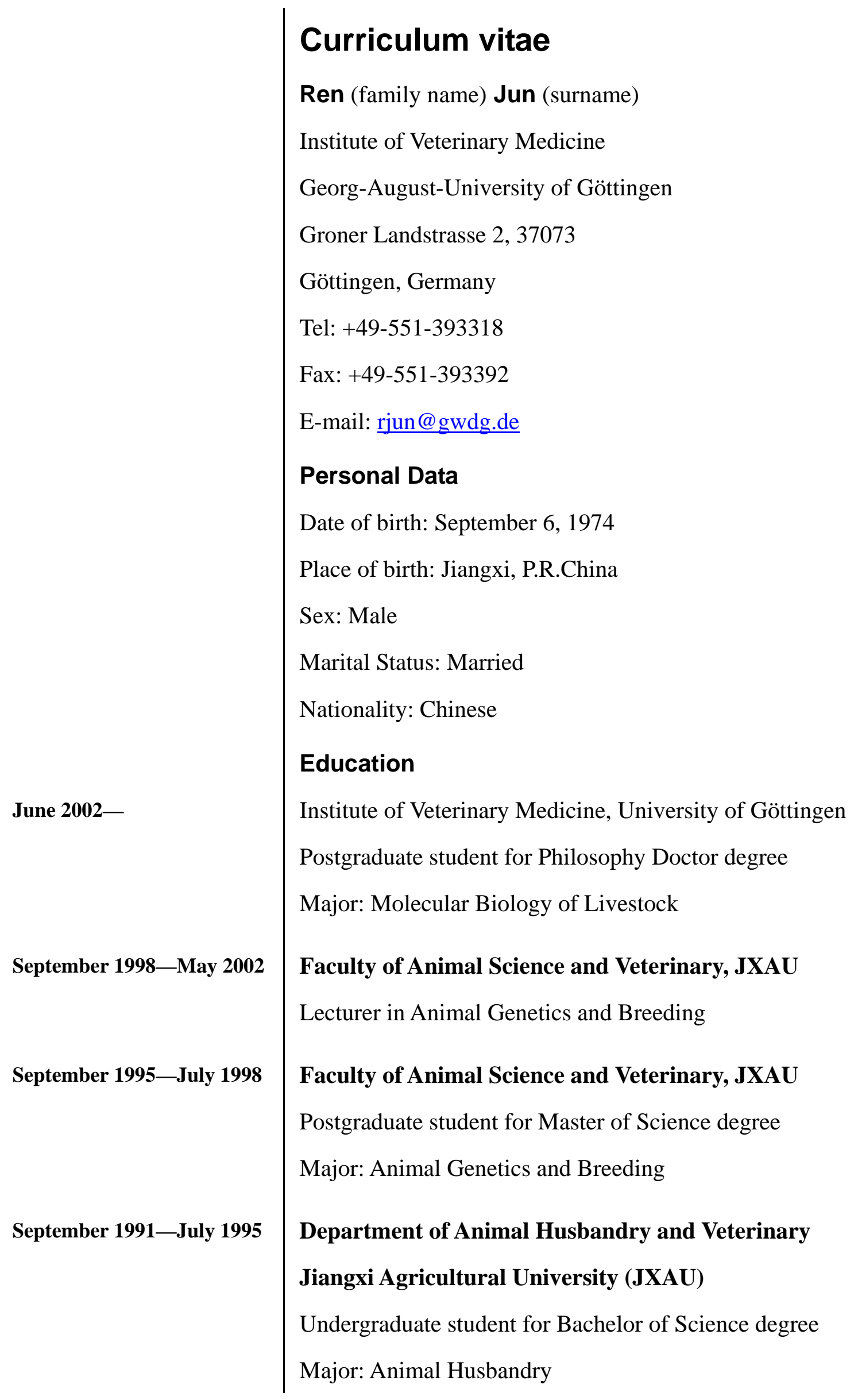

